\title{
Review
}

\section{The Practice of Korean Medicine: An Overview of Clinical Trials in Acupuncture}

\section{Yong-Suk Kim ${ }^{1}$, Hyungjoon Jun ${ }^{1}$, Younbyoung Chae ${ }^{2}$, Hi-Joon Park ${ }^{3}$, Bong Hyun Kim ${ }^{4}$, II-Moo Chang ${ }^{4}$, Sung-keel Kang ${ }^{5}$ and Hye-Jung Lee ${ }^{2}$}

\author{
${ }^{1}$ Department of Acupuncture and Moxibustion, College of Oriental Medicine, Kangnam Korean Hospital, \\ ${ }^{2}$ Department of Oriental Medical Science, Graduate School of East-West Medical Science, \\ ${ }^{3}$ Department of Meridian and Acupuncture, College of Korean Medicine, Kyung Hee University, \\ ${ }^{4}$ Natural Products Research Institute, Seoul National University, Seoul, South Korea and \\ ${ }^{5}$ Department of Acupuncture and Moxibustion, College of Oriental Medicine, Kyung Hee University, South Korea
}

\begin{abstract}
Acupuncture, one of the Oriental medical therapeutic techniques that can be traced back at least 2500 years, is growing in popularity all over the world. Korea has continued to develop its own unique tradition of medicine throughout its long history, and has formed different types of acupuncture methods. The purpose of this review is to summarize clinical case studies in acupuncture and related therapies, such as acupressure, electric acupuncture, auricular acupuncture and moxibustion in Korea. A survey of Korean journals revealed that a total of 124 studies were published from 1983 to 2001. Results obtained from the survey showed that most clinical studies using acupuncture, electric acupuncture, moxibustion and other traditional therapies could alleviate a relatively broad range of medical problems. However, it should be emphasized that almost all clinical case studies published in various local journals did not follow the 'good clinical practice' with respect to regulatory aspects. Since they were not conducted using the randomized double-blinded controls with a large sample size, all the results should be considered as therapeutic indications. This review is an attempt to show the scope of acupuncture in our country and the kind of diseases, after many years of clinical experience, that were deemed valid targets for clinical trials.
\end{abstract}

Keywords: acupuncture - clinical study - Korean acupuncture

\section{Introduction}

Acupuncture, one of the Oriental medical therapeutic techniques inherited from ancient East Asia, is gaining popularity in the West as an alternative and complementary therapeutic intervention (1). Acupuncture is now being used in Western medicine to treat postoperative-induced and chemotherapyinduced nausea and vomiting, postoperative dental pain, drug addiction, stroke rehabilitation and asthma (2). Korea has continued to develop its own unique traditional medicine

For reprints and all correspondence: Hye-Jung Lee, KMD, PhD, Department of Oriental Medical Science, Graduate School of East-West Medical Science, Kyung Hee University, 1 Seochonri, Kiheungeup, Younginshi, Kyungkido 449-701, South Korea. Tel: +82-31-201-2173; Fax: +82-31-206-9731;

E-mail: hjlee@khu.ac.kr throughout its long history, and has formed different types of acupuncture methods, apart from those of traditional Chinese medicine. An individualized approach based on constitutional energy traits and practical approaches applying new therapeutic modalities have been developed for treatment of disorders (3).

A large number of clinical studies using acupuncture have been performed to demonstrate its efficacy for many kinds of diseases, such as pain (headache, facial pain, neck pain, shoulder pain, lower back pain and knee pain), stroke, facial palsy and other diseases in Korea. A wide range of control groups were used in these studies. Acupuncture and acupuncturerelated therapies have been compared with various forms of control acupuncture, standard care, no treatment, baseline conditions and placebo acupuncture. These inconsistencies

(C) The Author (2005). Published by Oxford University Press. All rights reserved.

The online version of this article has been published under an open access model. Users are entitled to use, reproduce, disseminate, or display the open access version of this article for non-commercial purposes provided that: the original authorship is properly and fully attributed; the Journal and Oxford University Press are attributed as the original place of publication with the correct citation details given; if an article is subsequently reproduced or disseminated not in its entirety but only in part or as a derivative work this must be clearly indicated. For commercial re-use, please contact journals.permissions@oupjournals.org 
make the task of designing and performing systematic reviews or meta-analyses more difficult. However, non-controlled clinical trials might also be useful for the overview that they provide of what is known so far, with data that may inform future research. This review is an attempt to show a variety of applications for acupuncture treatments performed by the traditional Korean medical sector.

\section{Clinical Studies Using Acupuncture Treatment in Korea}

\section{Acupuncture for Pain}

\section{Headache}

Lee and Kim (4) analyzed the effect of acupuncture treatment at trigger points in 27 patients with headache. Lee et al. (5) compared the effect of acupuncture at trigger points with the effect of acupuncture at remote acupuncture points in patients who were diagnosed as having tension-type headaches. A clinical study of auricular acupuncture was also done in 55 patients with headaches (6). Clinical studies of acupuncture and auricular acupuncture for tension-type headaches were also performed $(7,8)$ (Table 1$)$.

\section{Facial Pain}

Temporomandibular disorder (TMD) is a musculoskeletal problem of the masticatory system and is quite commonly treated by acupuncture in the general population. It was reported that 8 and 10 cases, respectively, of TMD were treated by acupuncture $(9,10)$. Wang et al. (11) treated by Dong-Qi acupuncture and subjectively evaluated TMD and facial pain (Table 2).

\section{Neck Pain}

Chun and Lee (12) treated patients with chronic neck pain by using electric acupuncture $(0.3 \times 40 \mathrm{~mm}, 3.5-12 \mathrm{~Hz}, 9 \mathrm{~V})$. Kim and Lee (13) compared the group treated by both acupuncture and manipulation (chuna) treatment with the group only treated by acupuncture. A clinical study investigated the clinical applications of Oriental medical therapies including acupuncture treatment together with herbal therapy and hot pack for patients complaining of cervical pain caused by traffic accidents (14). It was reported that acupuncture treatment was effective in 50 patients with cervical pain (15). Lee and Lee (16) treated 25 patients with neck pain with electric acupuncture together with herbal therapy, cupping therapy and hot pack. It was also reported that acupuncture was effective in treating 50 patients with herniated cervical disc (17) (Table 3).

\section{Shoulder Pain}

Forty-three patients suffering from frozen shoulder during physical exercise were treated by acupuncture, moxibustion and electric acupuncture, and evaluated with Apley scratch

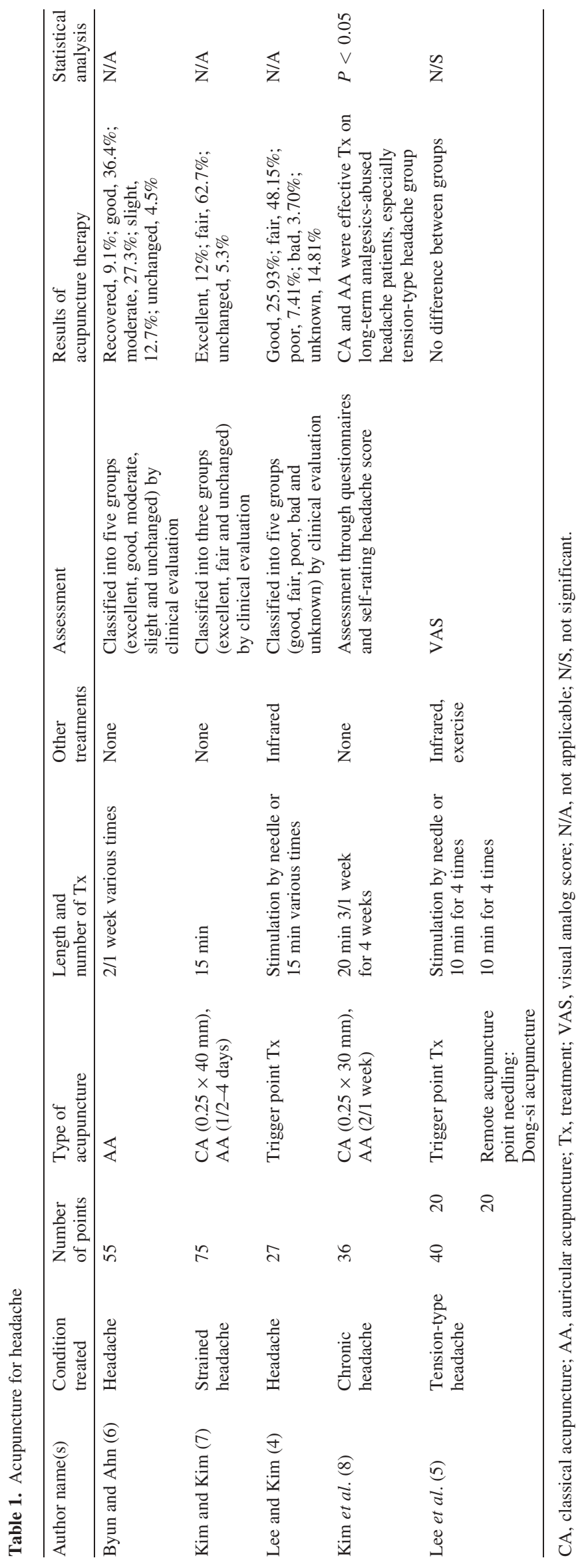


test. A total of $16.3 \%$ of them reported that the results of treatment were excellent and $30.2 \%$ of them reported that they were good (18). Cho and Lee (19) showed the correlation between digital infrared thermography image (DITI) data and changes in clinical symptoms after acupuncture treatment in patients with frozen shoulder (Table 4) (Fig. 1).

\section{Low Back Pain}

A series of 20 cases with lumbar herniated disc disease were treated by acupuncture (20). It was reported that acupuncture and herbal medicine alleviated the symptoms of the herniation of lumbar intervertebral disc (21-25). It was also reported that bee venom acupuncture (BVA) was beneficial for treating herniated intervertebral disc (HIVD) (26). Park et al. (27) performed clinical studies using acupuncture and manipulation treatment on 30 HIVD patients. It was found that microcurrent electrical neuromuscular stimulation was significantly effective in decreasing the visual analog scores of patients with lower back pain (28). Park et al. (29) reported a clinical study of the stability of the lumbosacral angle of 69 patients suffering from lower back pain. The morphological changes were demonstrated by computed tomographic scan examination of acute HIVD patients who underwent Oriental medical treatment (30).

A clinical study compared acupuncture with electric acupuncture for patients with HIVD (31). Park and Lee (32) compared the effect of electric acupuncture with the effect of Dong-si acupuncture on patients with HIVD. Lee and Hwang (33) compared electric acupuncture with electric acupuncture and Saam acupuncture in HIVD patients. Yoon et al. (34) compared acupuncture at A-shi points with acupuncture on acupuncture points in HIVD patients. Chae et al. (35) compared conventional acupuncture with Eight constitution acupuncture and demonstrated that Eight constitutional acupuncture was more beneficial than conventional acupuncture for the treatment of HIVD patients.

Electric acupuncture decreased the frequency of radiating pain in lumbar spondylosis (36). Clinical studies evaluated Oriental medical treatment and manipulation therapy in patients with scoliosis $(37,38)$. Kim (39) reported the results of 96 patients suffering from sciatica with lower back pain treated by acupuncture and herbal medicine. It was reported that acupuncture, moxibustion and herbal medicine were useful for acute back pain (40). Lee and Yin (41) also reported a clinical study of BVA on ankylosing spondylitis. Lee et al. (42) performed a clinical study on acupuncture for stable thoracolumbar vertebral fractures. It was reported that acupuncture, electric acupuncture, acupuncture at Hua-TuoJia-Ji-Xue were useful for the treatment of thoracolumbar compression fracture (43-45). Han (46) treated degenerated stenosis patients (37 cases), and Kim et al. (47) evaluated the clinical results of the spondylolisthesis patients treated by Oriental medical methods.

Lee et al. evaluated acupuncture treatment for HIVD and stable compression fracture patients using DITI $(48,49)$. 


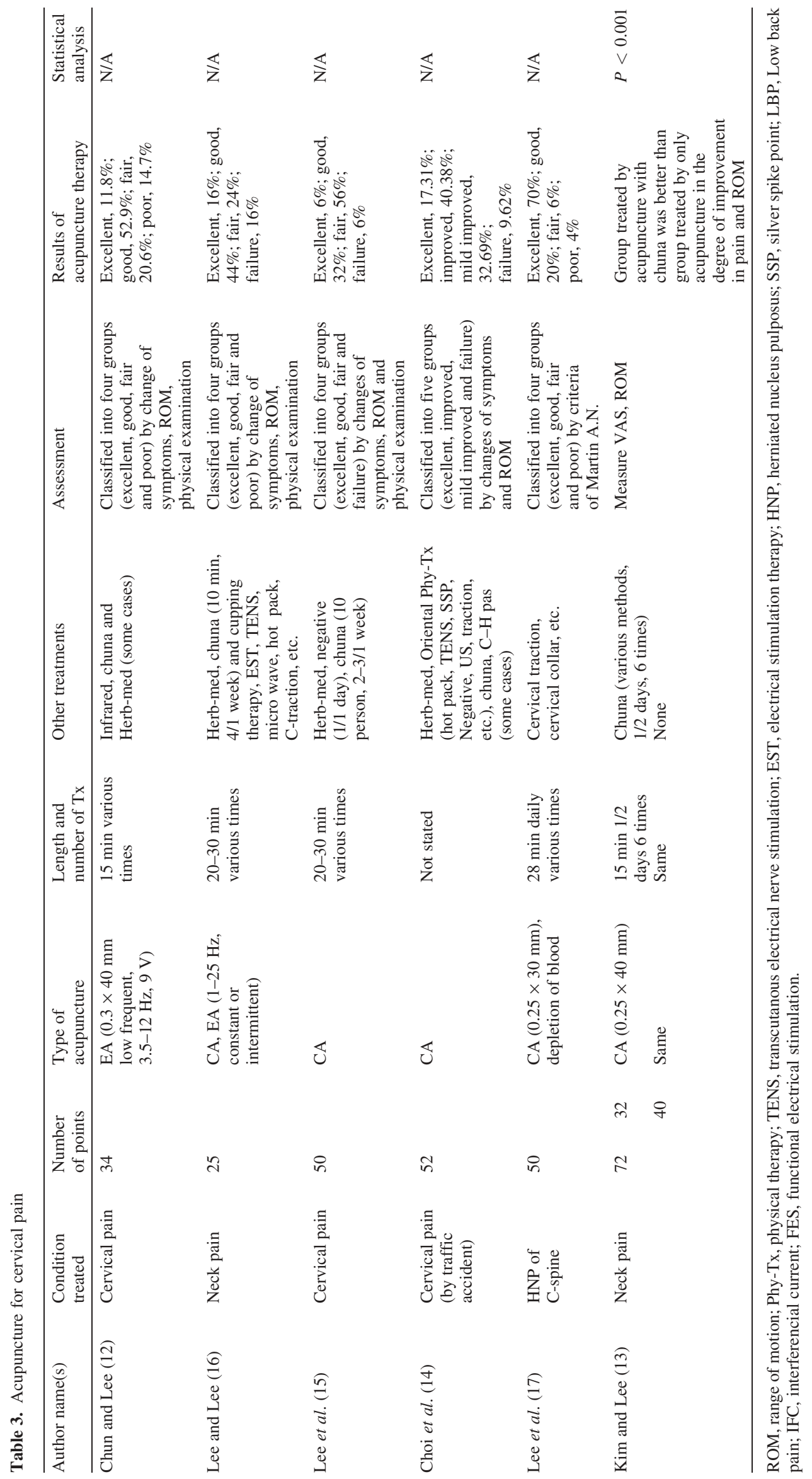




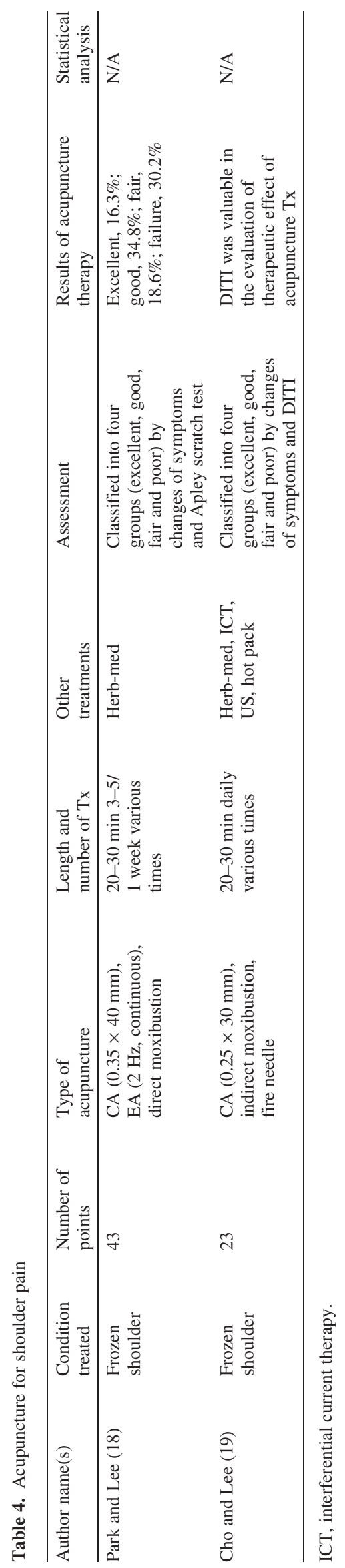

Cho and Kim (50) compared the acupuncture with electric acupuncture for HIVD patients using DITI. Hur et al. (51) investigated changes in the clinical symptoms of patients with spondylolisthesis after acupuncture treatment and evaluated alterations in DITI. A clinical study also reported a relationship between cigarette smoking and the result of Oriental medical treatment for lower back pain (52). Heo and coworkers studied the treatment of lower back pain and sciatica and found some correlation in the rate of alleviation with alterations in Moire topography $(53,54)$ (Table 5).

\section{Knee Joint Pain}

It was reported that acupuncture was useful for the treatment of degenerative arthritis of knee joints (55-57). Woo et al. (58) evaluated the clinical effect of acupuncture on microtraumatic injuries of the knee joint. Kim and Lee compared acupuncture with BVA for osteoarthritis $(59,60)$. Hwang et al. (61) measured the change of C-reactive protein (CRP), erythrocyte sedimentation rate (ESR) and rheumatoid arthritis (RA) factor, and the satisfactory assessment after BVA treatment in RA patients. Hwang (62) treated RA patients with herbal acupuncture (HA) and evaluated CRP, ESR, RA factor and immunoglobulin $\mathrm{G}$ and $\mathrm{M}$ (Table 6).

\section{Other Painful Diseases}

Electrical acupuncture stimulation was very useful to relieve pain that had not responded to various conventional medications including nerve blocks, neurosurgical intervention and neuropolitics (63). Cho et al. (64) compared acupuncture treatment and analgesics in postthoracotomy pain control. It was reported that venesection, a therapeutic method of sucking out non-physiological blood, alleviated pain induced by blood circulation dysfunction (65). Kim et al. (66) compared acupuncture treatment with trigger point treatment in ankle sprain patients. Bang et al. (67) carried out a clinical study on patients with humeral lateral epicondylitis or tennis elbow. Seung and Ahn (68) investigated the effect of moxibustion on the immune activity in the treatment of patients. Acupuncture treatment was very beneficial for acute gout (69). It was also demonstrated that acupuncture at acupoints on the non-injured side were as effective as acupuncture at acupoints on the injured side in ankle sprain patients (70) (Table 7) (Fig. 2).

\section{Acupuncture for Stroke}

\section{Stroke}

Ha et al. (71) reported a clinical study of acupuncture and scalp acupuncture on stroke patients ( 29 cases). Lee et al. (72) evaluated the change of blood pressure and body temperature of the stroke patients after venesection at Sybsun points, 10 acupoints located at the tips of all fingers and demonstrated that venesection at Sybsun points could alleviate hypertension in stroke patients. Park et al. (73) examined electrical stimulation at GV26 and CV24 on blood pressure, heart rate and cerebral 


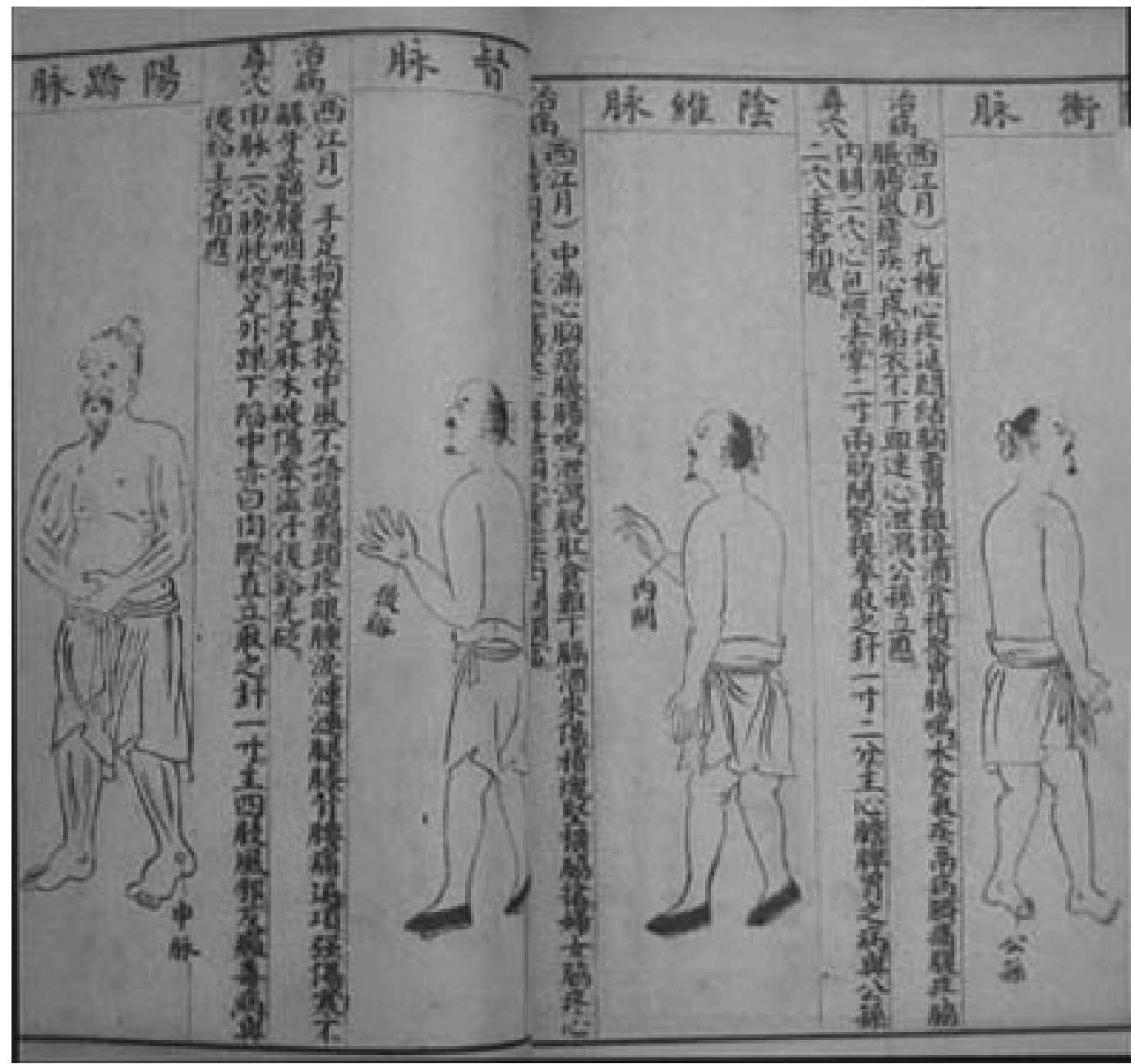

Figure 1. 'Acu-moxibustion Being Easy to Learn', published in the Ching dynasty, 18th century. (Courtesy of Dr Kim Nam-Il, Department of Medical History, College of Oriental Medicine, Kyung Hee University, Seoul, South Korea.)

blood flow $(\mathrm{CBF})$ in ischemic stroke patients with transcranial doppler sonography. Ahn et al. (74) investigated change in $24 \mathrm{~h}$ blood pressure after auricular acupuncture treatment in stroke patients using an ambulatory blood pressure monitor. Kang et al. (75) compared acupuncture at ST36 and LI11 with stimulation at non-acupoints near these acupoints for the modulation of hypertension of acute stroke patients. Moon et al. (76) compared acupuncture at ipsilateral points with that at contralateral points on the cerebral blood flow (CBF) in ischemic stroke patients (Table 8).

\section{Poststroke Diseases}

Electric acupuncture could alleviate shoulder pain in cerebrovascular attack patients (77). It was demonstrated that BVA at LI15 and SI10 decreased visual analog scale of pain severity and increased painless passive range of motion of shoulder eternal rotation in hemiplegic shoulder pain patients (78). Kang and Baik (79) compared the therapeutic value of transcutanous electrical nerve stimulation with interferential current therapy, infrared or hot pack treatments for shoulder pain in cerebrovascular attack patients. Lee and Lee (80) evaluated the effect of acupuncture and electric acupuncture on shoulder hand syndrome by using DITI. Kang et al. (81) examined the balanced bladder time and residual urine volume and demonstrated the clinical efficacy of moxibustion at CV3, CV4 and CV6 in patients with voiding dysfunction after a cerebrovascular accident (Table 9).

\section{Acupuncture for Facial Palsy}

Acupuncture treatment was beneficial in 72 cases of patients with facial paralysis (82). Moreover, electric acupuncture was better than needling in the treatment of patients with peripheral facial nerve paralysis (83). The effect of Hominis placenta acupuncture, a kind of HA, on Bell's palsy was reported (84). It was demonstrated that Saam acupuncture at liver and stomach tonification points could treat peripheral facial palsy (85). Cho et al. observed the change of clinical symptoms and DITI, showing the benefits of acupuncture and herbal medicine in patients with Bell's palsy $(86,87)$. 


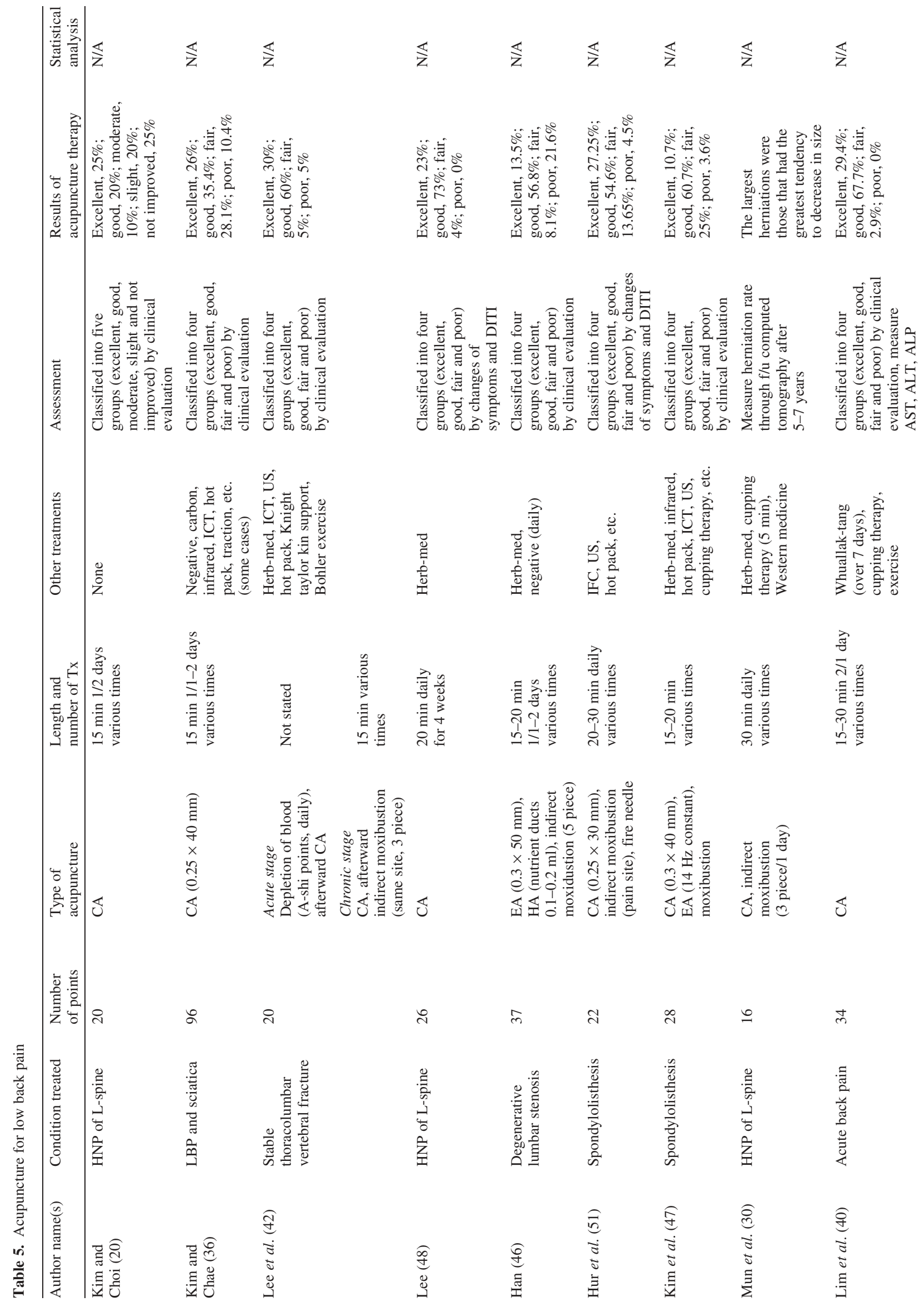




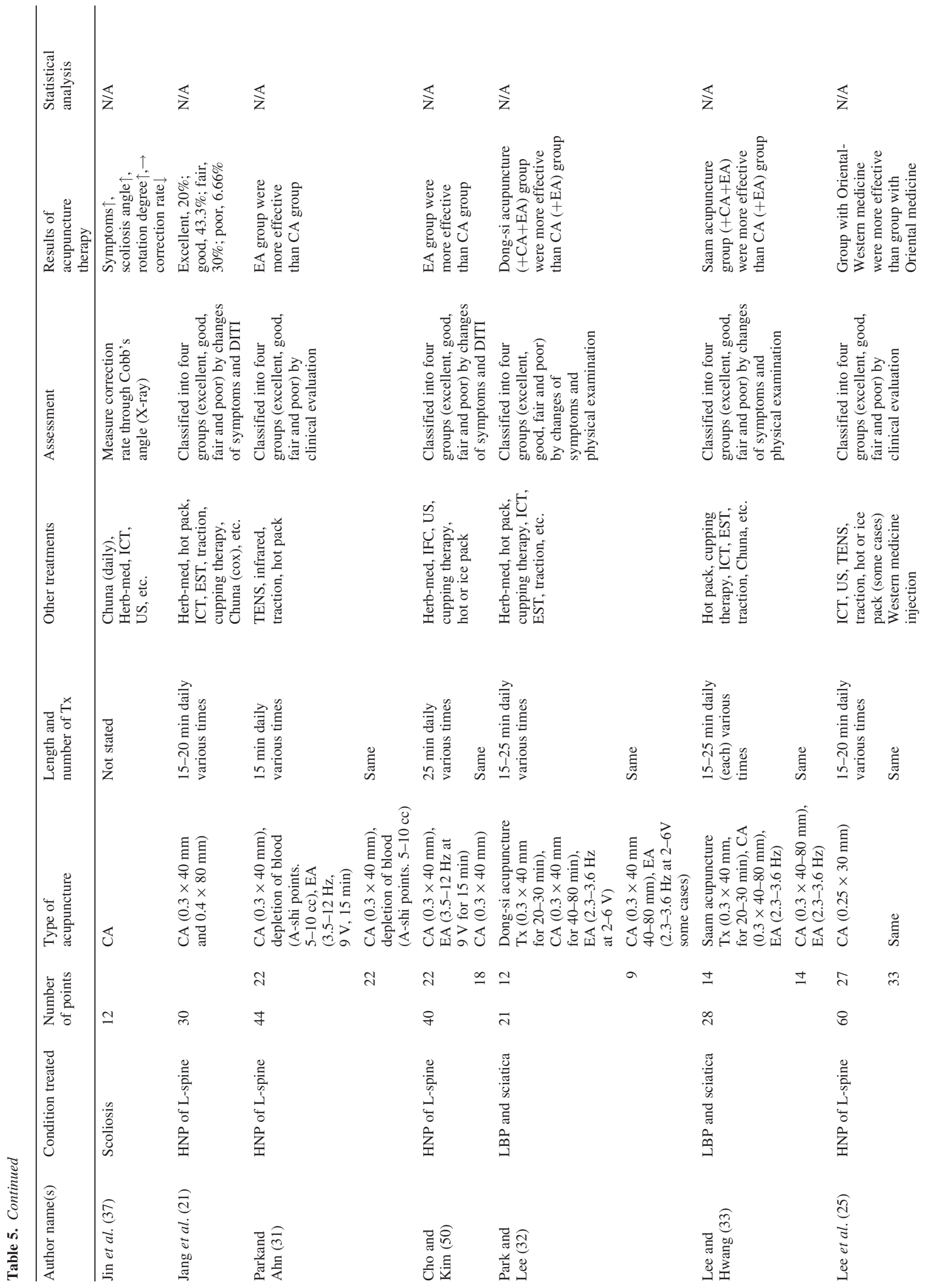




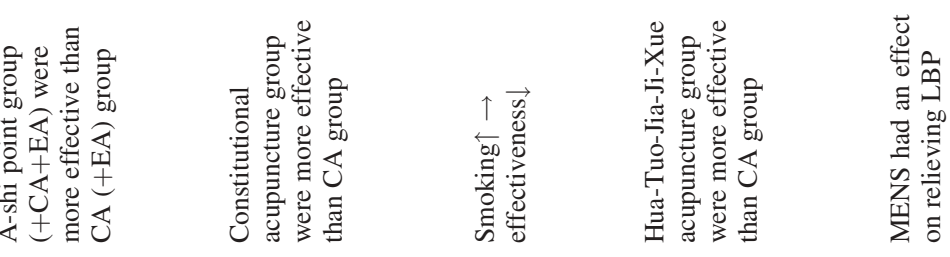

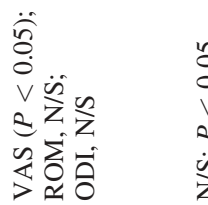

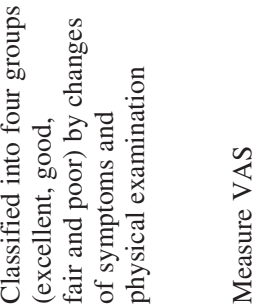
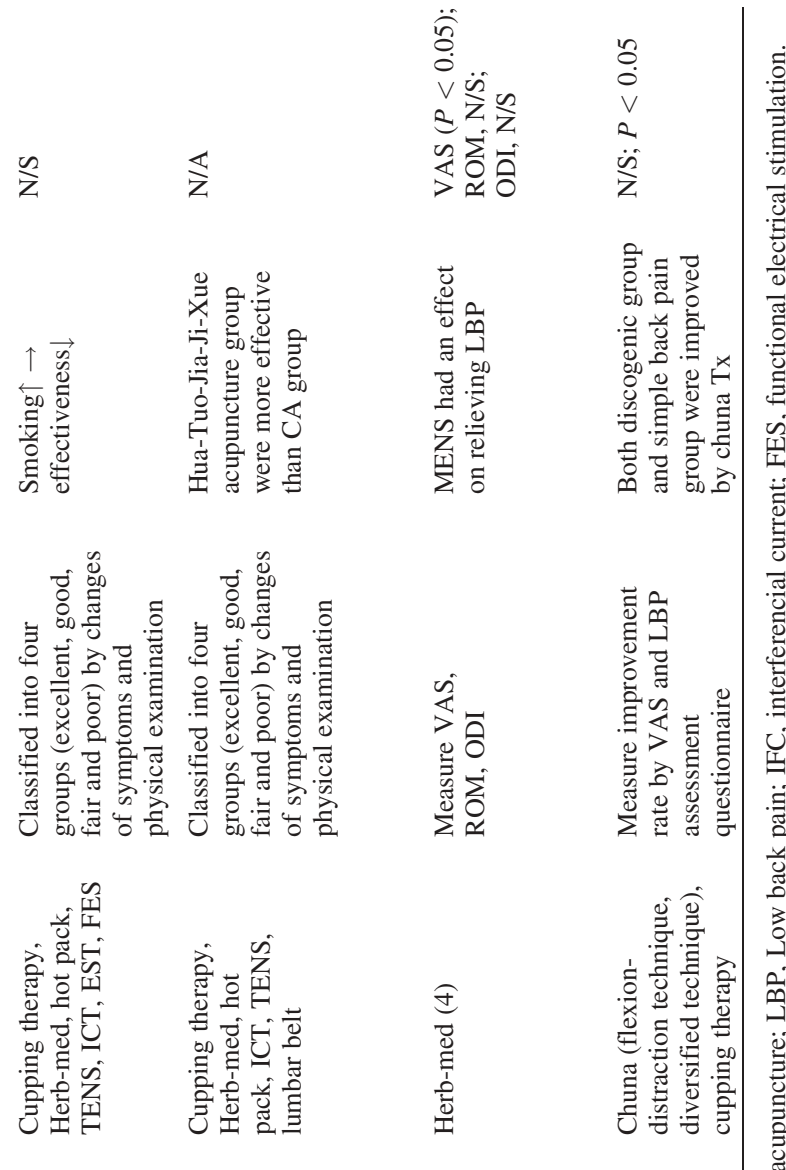

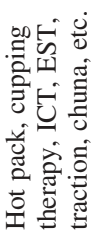
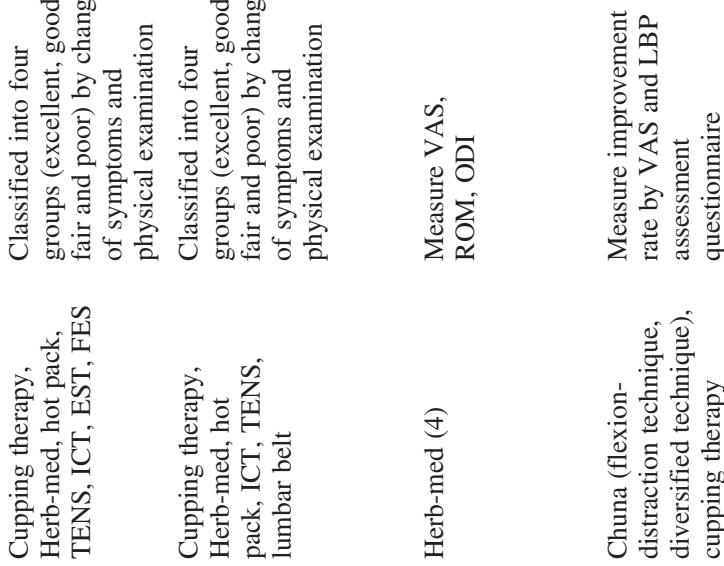

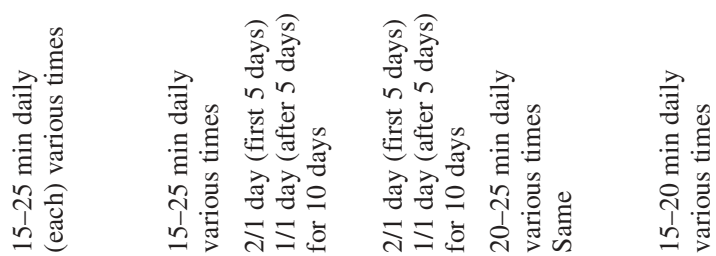

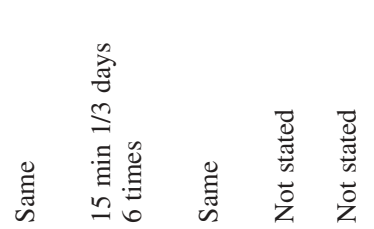

灵

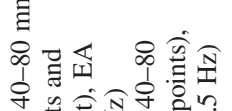

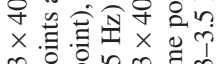

m.

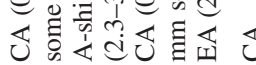

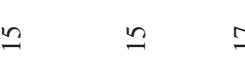

요

สิ

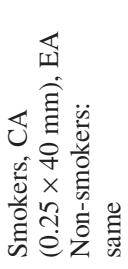

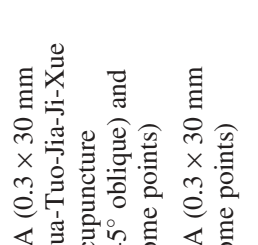

हี

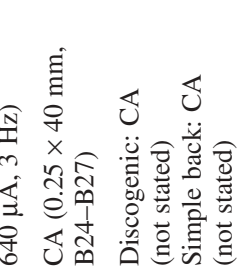

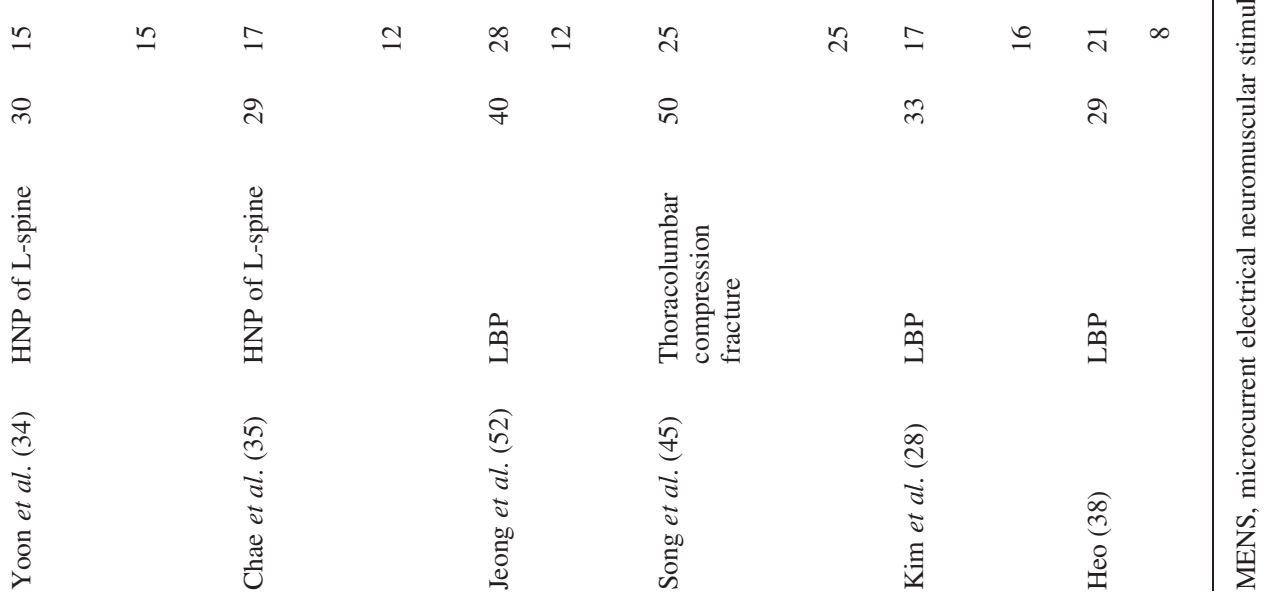




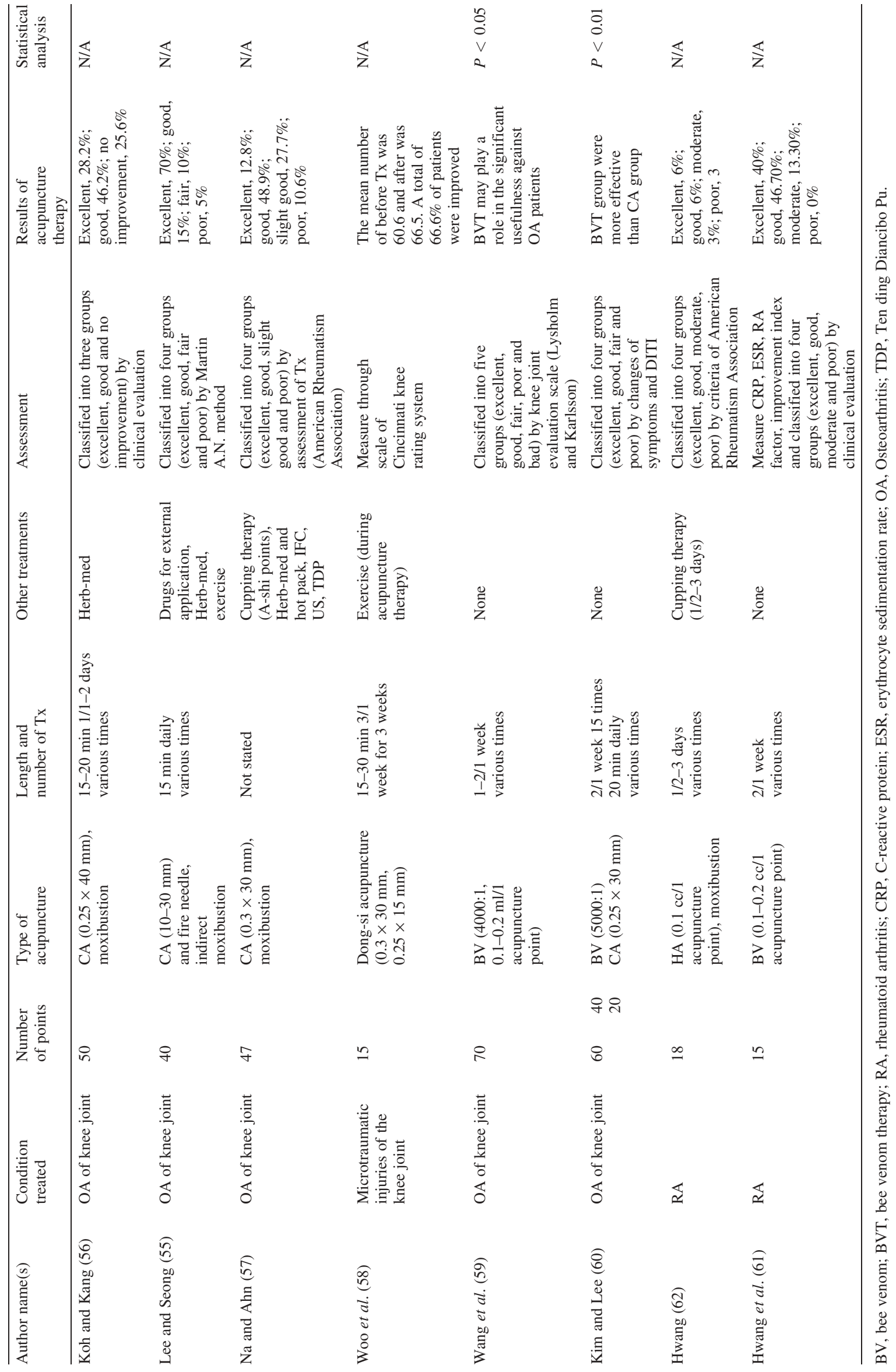




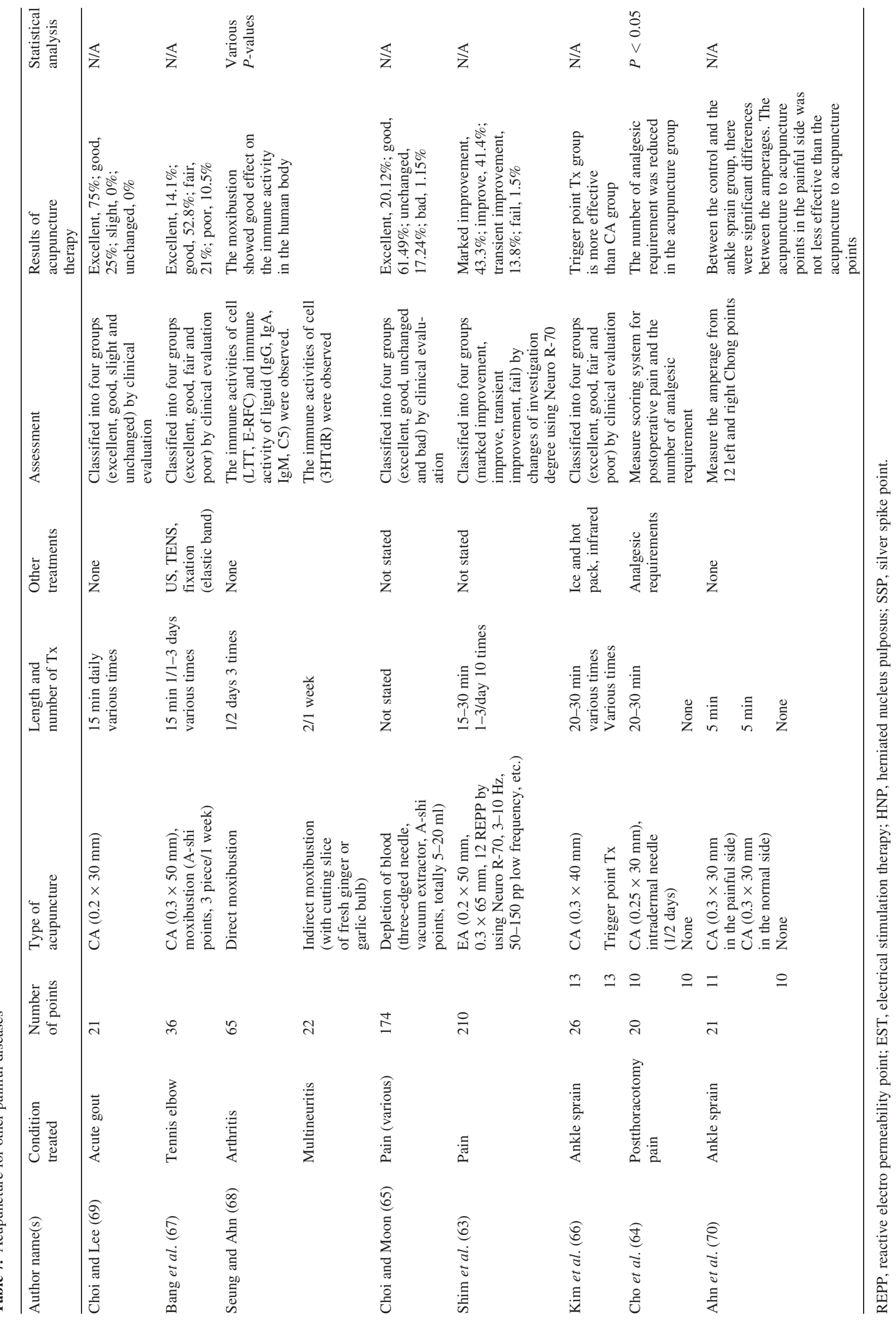




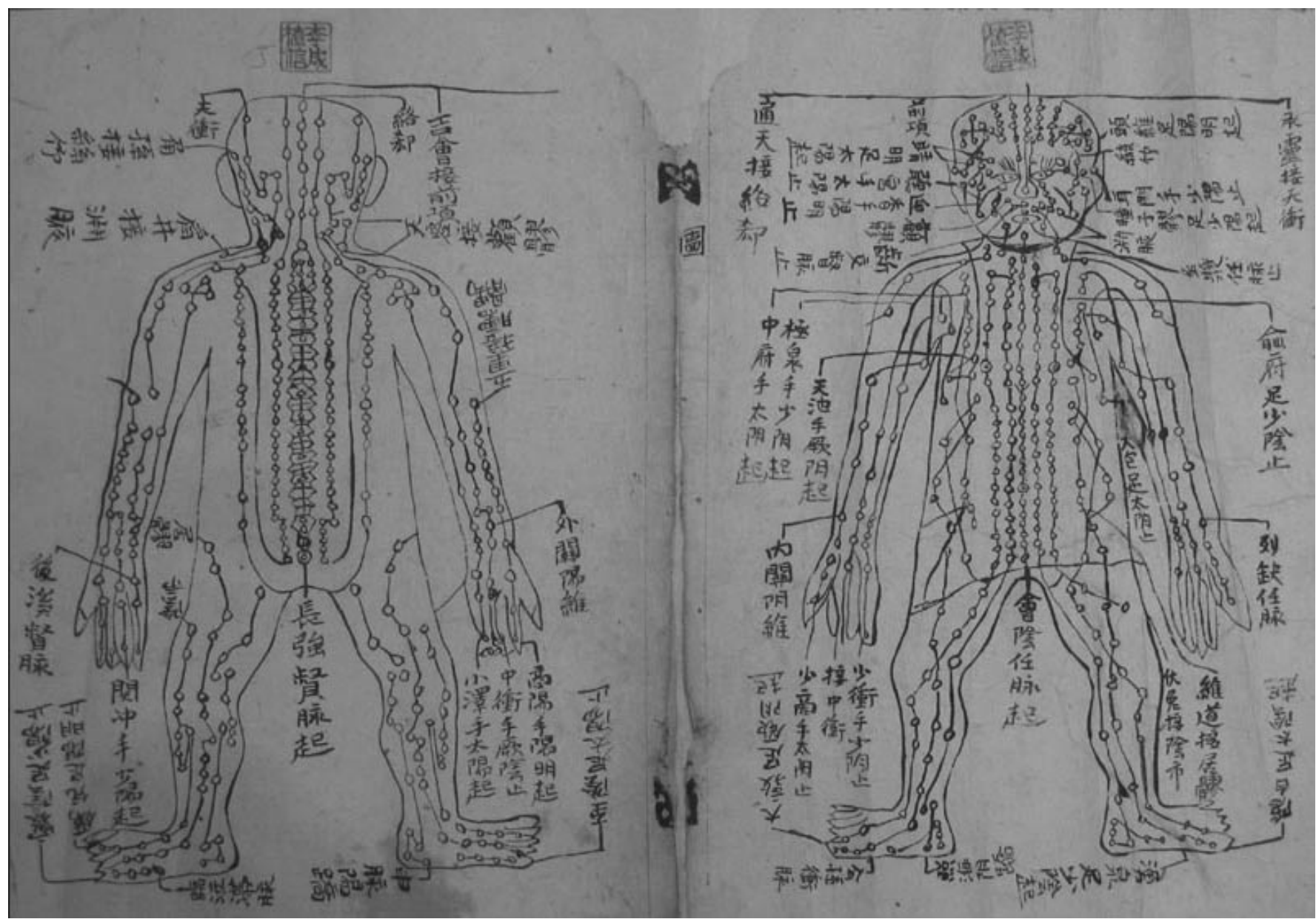

Figure 2. An excerpt from 'The Simplified Diagram of Mingtang' published in the Ming Dynasty. 'Mingtang' means mansion-house or hall and acupoints are called 'the house of Qi'. This may be another correlating factor between 'acupoint' and 'Mingtang'. Since 'Mingtang' gradually became a substitute for 'acupoint', the so-called 'Mingtang diagram' generally referred to 'the diagram of acupoints'. (Courtesy of Dr Kim Nam-Il, Department of Medical History, College of Oriental Medicine, Kyung Hee University, Seoul, South Korea.)

Kang et al. compared a group treated by Oriental-Western treatment with a group treated by Oriental medical therapy by evaluating House-Brackmeann grading system and made a detailed evaluation of facial symmetry of Pillsbury and Fisch $(88,89)$. Kim et al. $(89)$ compared a group treated by both acupuncture and herbal medicine with a group treated by acupuncture in patients of facial nerve paralysis and demonstrated that the symptoms were improved in both groups. Kwon et al. (90) compared a group treated by conventional Oriental medicine therapy with a group treated by conventional Oriental medicine therapy and indirect moxibustion at ST4 and ST8 in peripheral facial paralysis patients (Table 10).

\section{Acupuncture for Other Conditions}

\section{Eye Disease (Opthalopathy)}

Acupuncture and venesection were useful in treating 22 patients who suffered from acute infectious conjunctivitis (91). Kim and Chae (92) reported 32 patients with cataract or glaucoma who were treated by Oriental medicine and acupuncture. The therapeutic effect of acupuncture and moxibustion on the sight of near-sighted patients was also reported $(93,94)$. Clinical studies were carried out to demonstrate the effect of Oriental medicine and acupuncture on amblyopia (95) (Table 11).

\section{Nose Disease (Rhinopathy)}

Acupuncture was effective in the treatment of allergic rhinitis in 30 patients (96). Nasal acupuncture therapy was investigated to treat the chronic paranasal sinusitis and nasal obstruction $(97,98)$ (Table 12).

\section{Ear Disease (Otopathy)}

Clinical studies were carried out to investigate acupuncture, moxibustion and venesection for tinnitus $(99,100)$. It was reported that acupuncture at TE5, GI41, TE6 SI5, GI38, KI2 and venesection improved symptoms of patients with otitis media with effusion (101) (Table 13). 


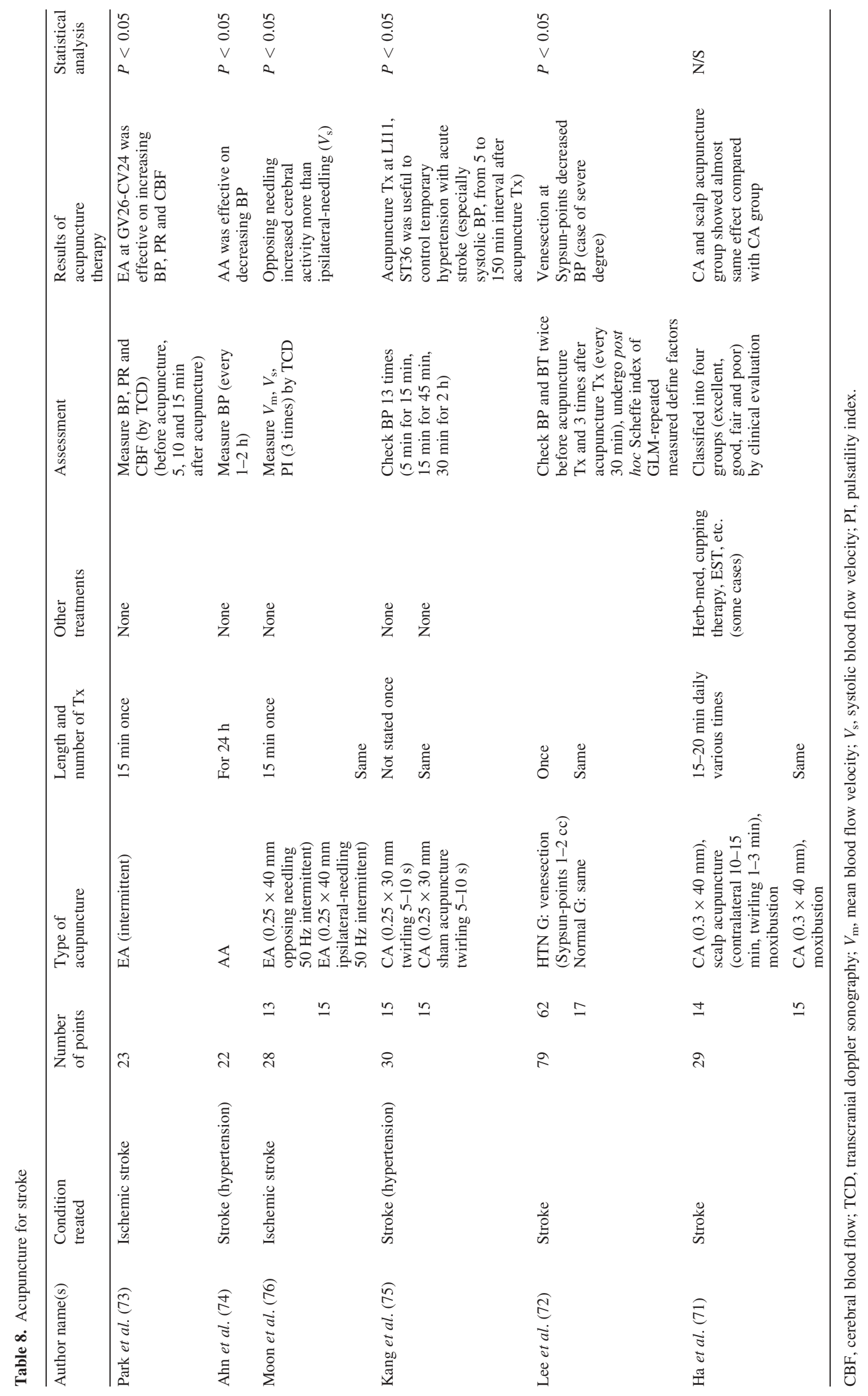




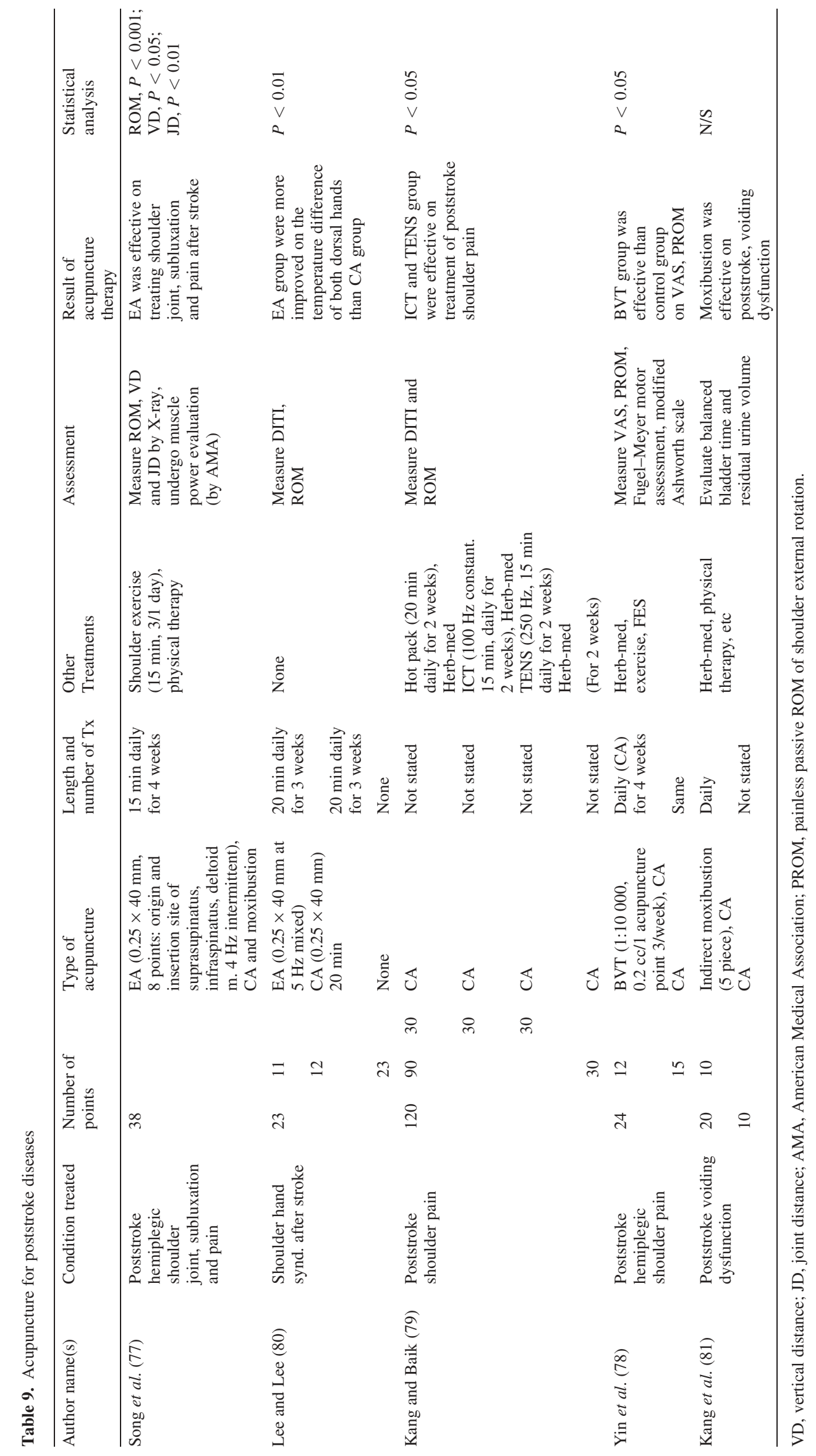




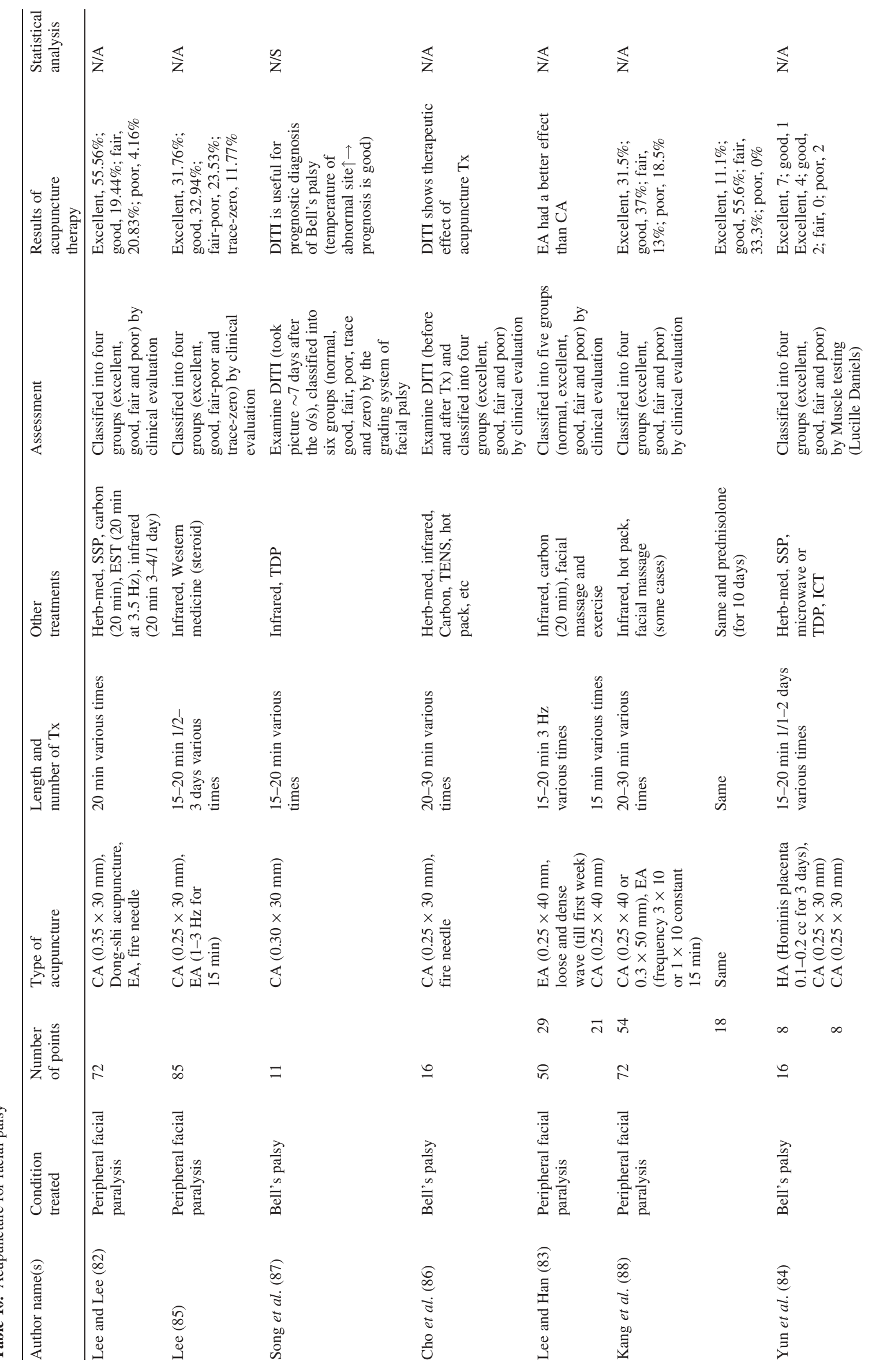




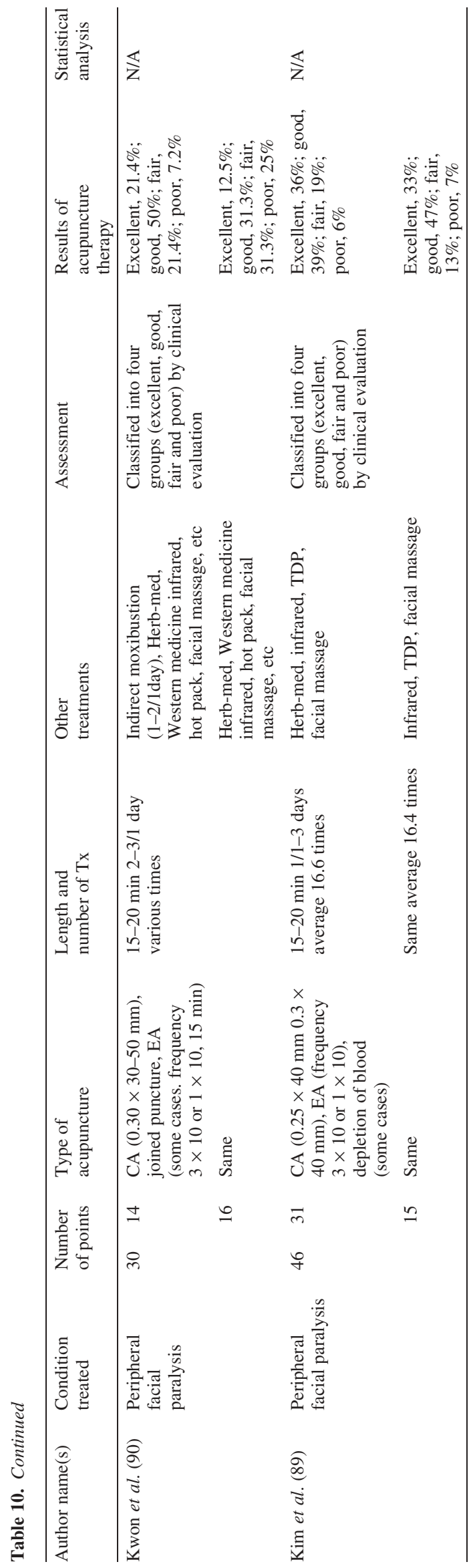

\section{Skin Disease (Dermatology)}

It was reported that acupuncture and herbal medicine were effective in the treatment of acne in 125 patients (102). It was also found that acupuncture and herbal medicine improved the symptoms of the acne patients (103) (Table 14).

\section{Hypertension}

Clinical studies with auricular acupuncture were performed on 23 patients with hypertension (104). Lee et al. (105) examined moxibustion at LI11 and CV4 for blood pressure of hypertension patients (Table 15).

\section{Smoking and Drinking Cessation}

Auricular acupuncture to stop smoking (106-110). Kim et al . investigated the effect of auricular acupuncture on cessation of drinking in alcoholic patients $(111,112)$. It was reported that auricular acupuncture and herbal medicine were effective for quitting drinking (113) (Table 16).

\section{Obesity}

Electric acupuncture decreased body weight, abdominal length, size of waist and body mass index $(114,115)$. Lee and Kim (116) compared auricular acupuncture combined with acupuncture with auricular acupuncture combined with herbal medicine for the treating obesity by measuring body weight and percentage of body fat (Table 17).

\section{Nausea and Vomiting}

Auricular acupuncture on sympathetic, stomach, shenmen and occiput points for postoperative nausea and vomiting in 100 female patients undergoing transabdominal hysterectomy. It was demonstrated that electric acupuncture at PC6 and PC7 was very effective in preventing nausea, retching and vomiting (118) (Table 18).

\section{Obstetrics and Gynecology}

Electric stimulation at acupuncture points significantly shortened the delivery time and attenuated the pain during delivery (119). Moreover, endometrial curettage was successfully performed on 31 female patients under acupuncture anesthesia (120) (Table 19).

\section{Others}

Moxibustion could have an effect on peripheral circulation (121). Ahn et al. (122) examined the temperature change of external genitalia in patients with impotence after herbal medicine and acupuncture treatment. Auricular acupuncture altered hormone and energy metabolism during weight control of athletes (123) (Table 20). 


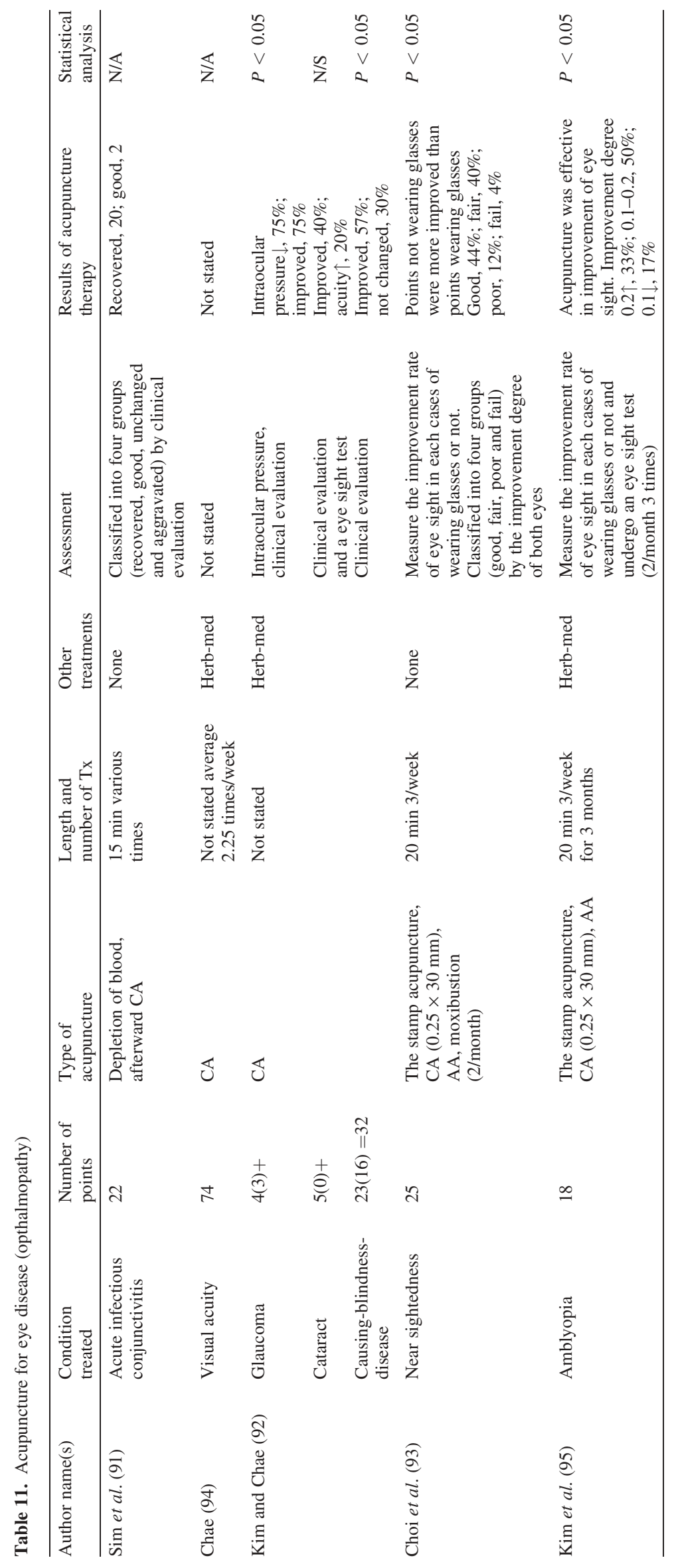



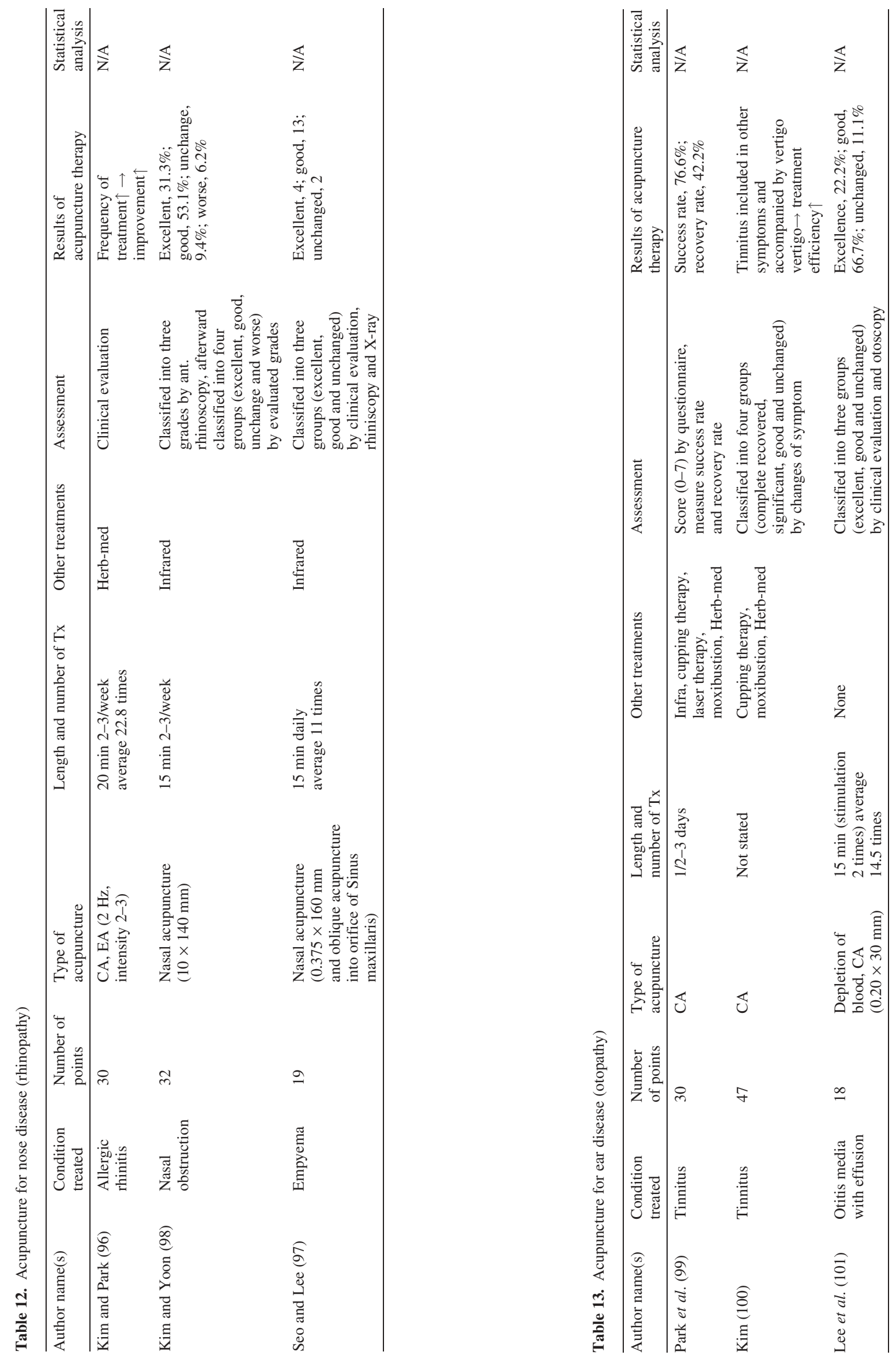


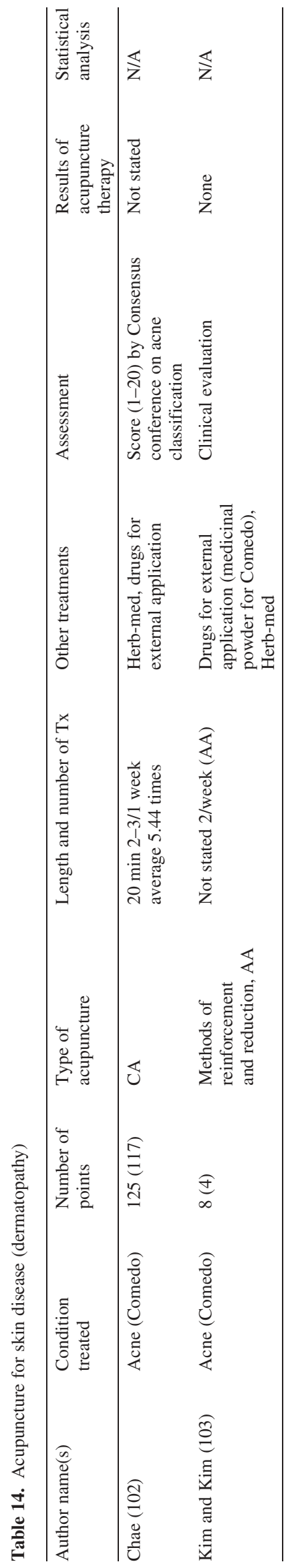

\section{Acupuncture for Human Study}

Acupuncture stimulation significantly decreased electrical resistance under the adiaphoresis, suggesting that the decrease of electrical resistance is caused not only by sweat secretion but also by other internal resistance (124). Youn et al. (125) reported a strong correlation between acupuncture at KI6 and cortical activation in the motor-related region of the human brain by using fMRI. Acupuncture at LI4 in the left hand increased regional $\mathrm{CBF}$ ( $\mathrm{rCBF}$ ) in the right parietal lobe, middle temporal gyrus and inferior occipital lobe, and electric acupuncture at ST36 on the right side increased rCBF in the left temporal lobe, the inferior frontal lobe and cerebellar hemisphere using single photon emission computed tomography $(126,127)$. It was shown that acupuncture at LI4 and LV3 could ipsilaterally enlarge a blind spot map (128).

Several studies were performed to examine if acupuncture at LI4 changed skin temperature in the LI4 area of the hand, LI11 area of the arm, LI20 area of the face and ST25 area of the abdomen by using DITI (129-135). It was also examined to see whether the alteration of acupuncture manipulation method could change the temperature in these regions of the body $(136,137)$. Other studies were performed to investigate the effects of acupuncture at LU9 by thermal change in the five shu points or LU9 and LU1 areas of lung meridian $(138,139)$. Yook et al. (140) examined whether HA at BL12, BL13, BL41 and BL42 could affect local thermal change by using DITI. Kim et al. (141) examined whether acupuncture at the WuHu acupoint could affect thermal change in the ankle region (Table 21).

\section{Discussion}

A large number of clinical studies have used acupuncture; electric acupuncture, moxibustion and other traditional therapies to target a relatively broad range of medical problems, primarily pain and stroke. Moreover, acupuncture has been widely used for treatment of facial palsy, obesity, hypertension, nausea and vomiting, and many other diseases. However, as mentioned in the beginning of this report, the studies had various weaknesses such as inadequate sample size, inappropriate control treatment, inadequate follow-up, inadequate control of non-specific effects, inadequate reporting of side effects and a few studies' failure to replicate results. These concerns make it difficult to draw clear conclusions about efficacy in most areas where acupuncture has been tested.

A number of systematic reviews on acupuncture for specific conditions have recently been published, including an extensive systematic review on chronic pain, with a far reaching search strategy and a way of scoring trial methodology (142). Recently, the best evidence synthesis review showed that there was only limited evidence that acupuncture is more effective than no treatment (waiting list) and inconclusive evidence that acupuncture is more effective than inert placebo, sham acupuncture or standard medical care (143). In addition, the 

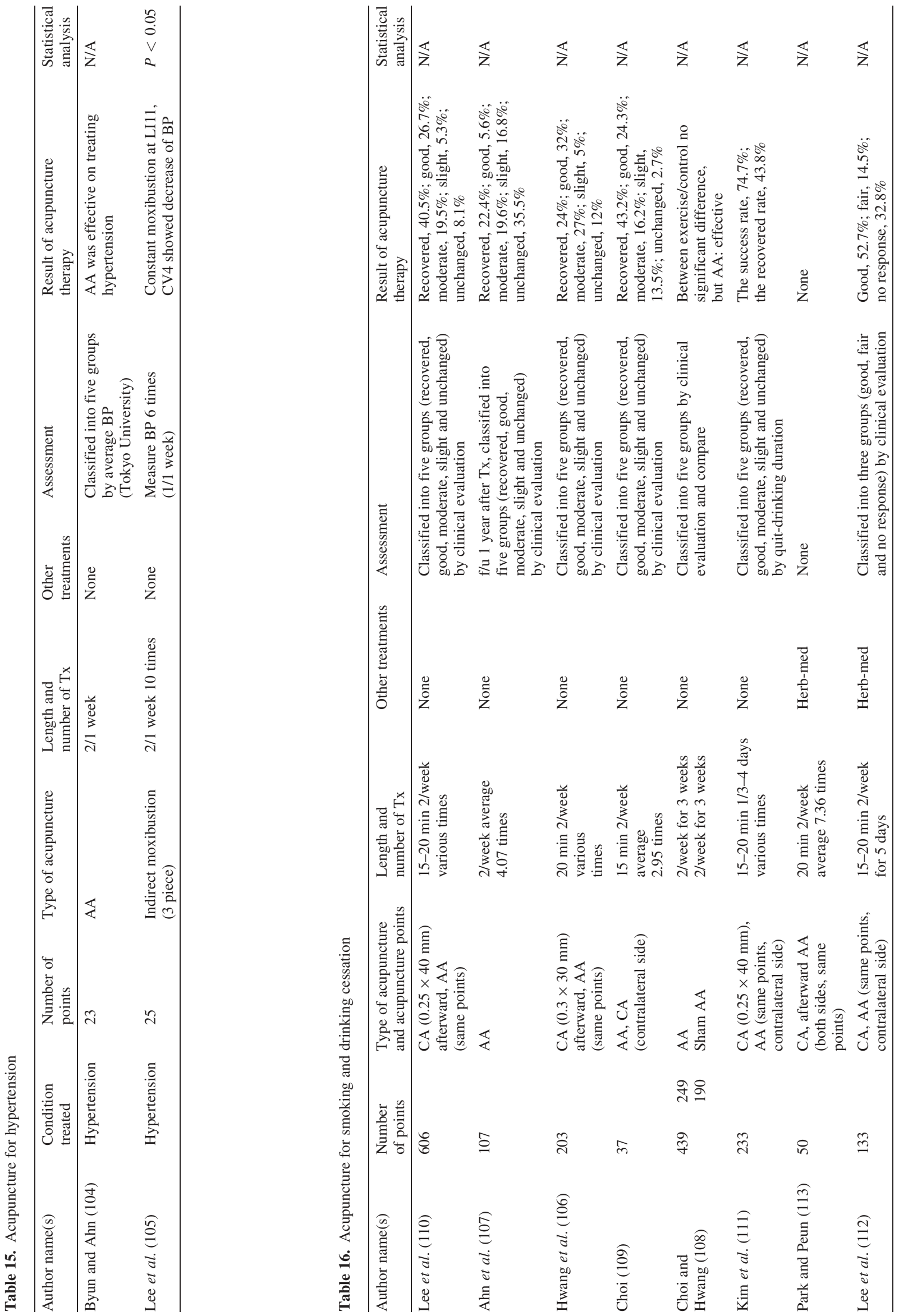


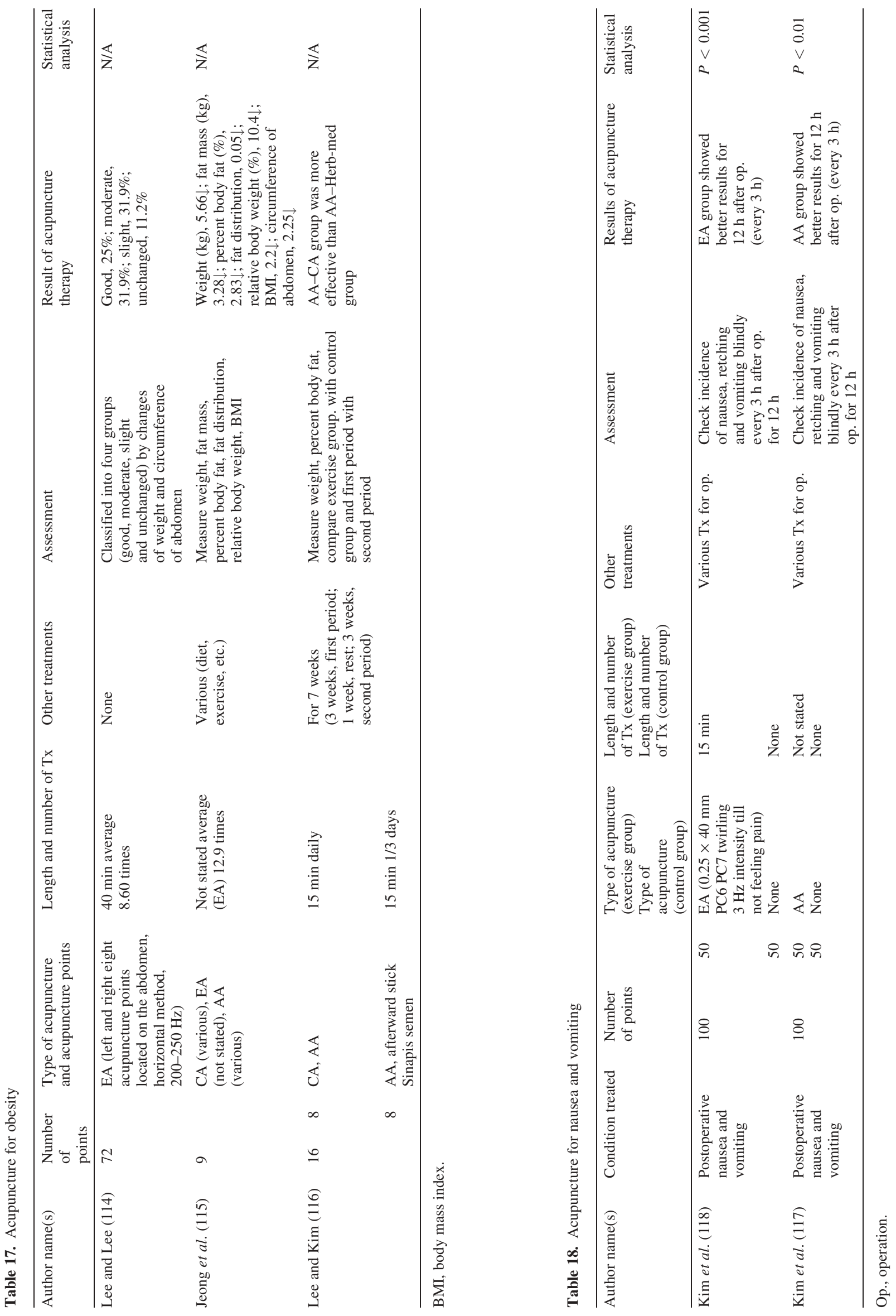




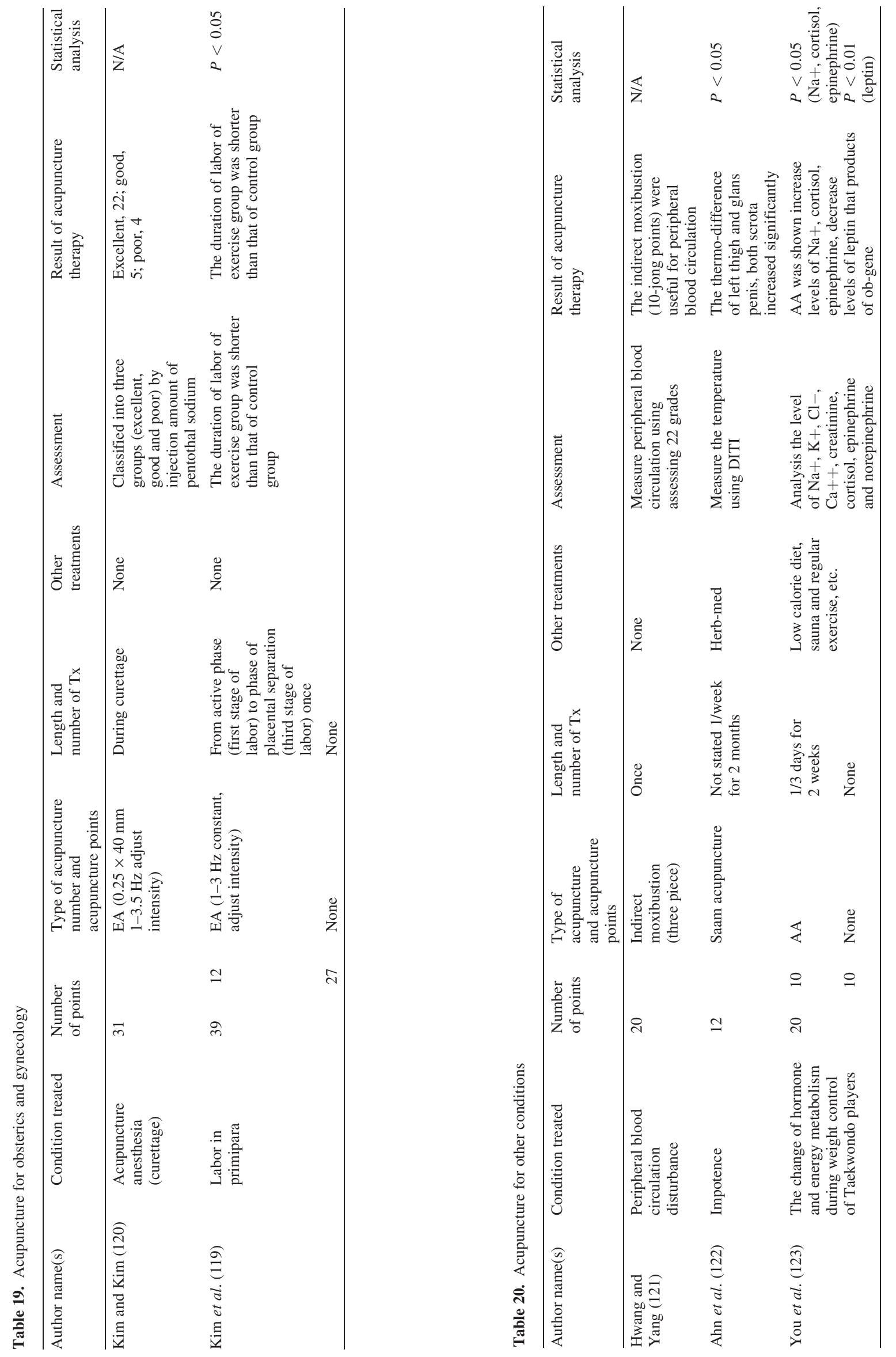




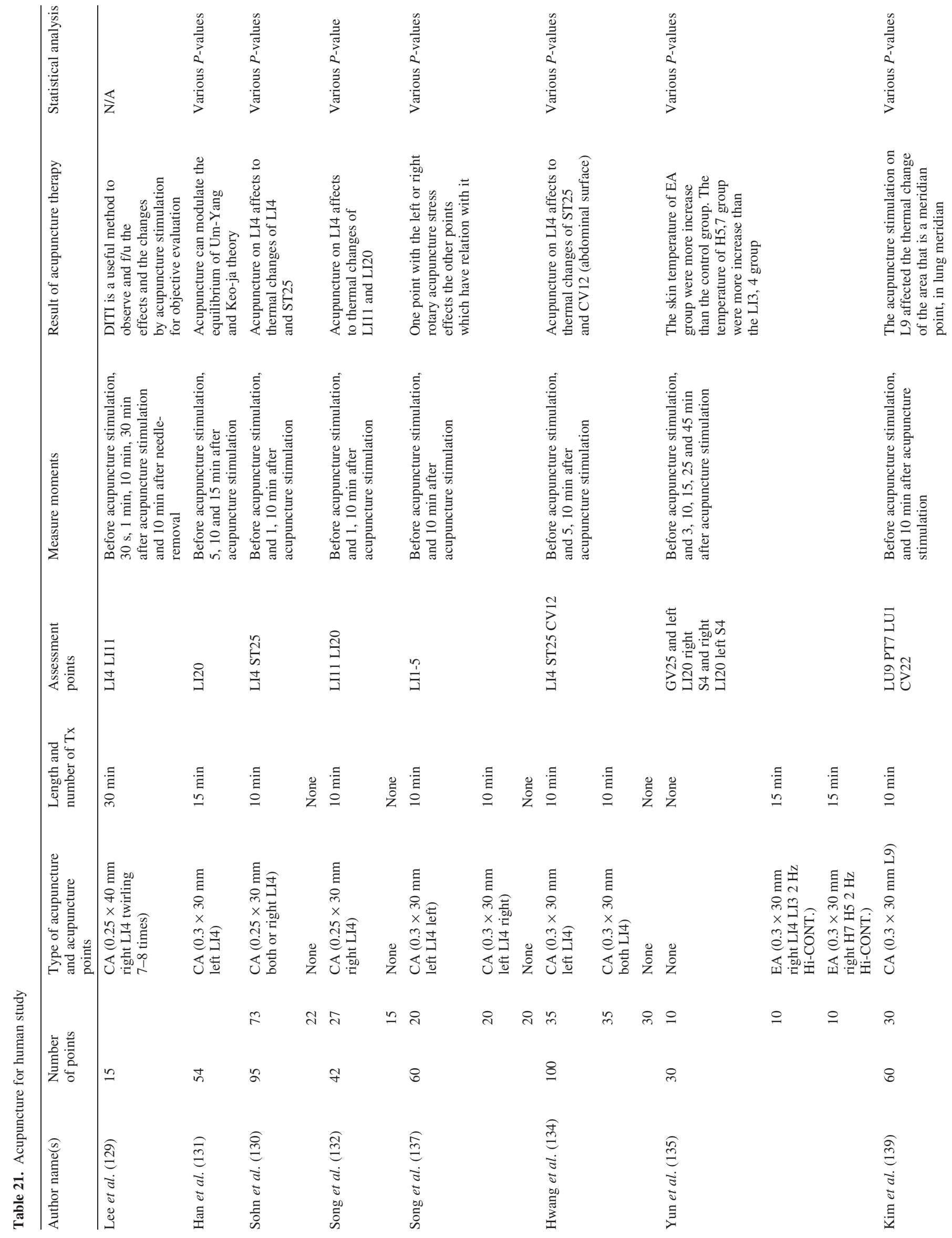




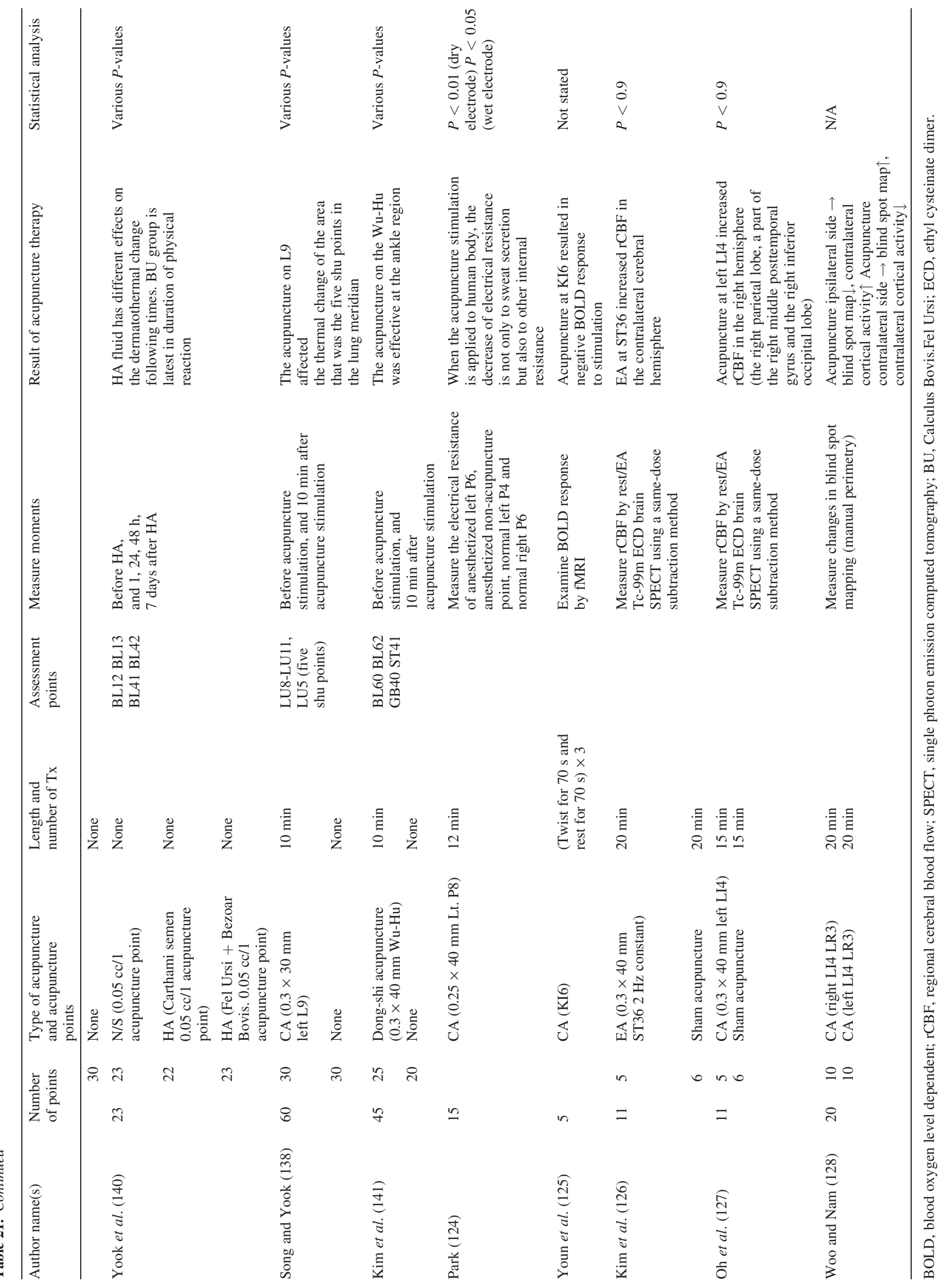


evidence of rigorous randomized controlled trials showed that there was no compelling evidence to show that acupuncture is effective in stroke rehabilitation (144). Yet, as clinicians who treat patients with acupuncture, we have success in these treatments where no efficacy is found. This is due to a complex set of problems at the heart of which is the establishment of a standard for the treatment of the control group. This article is not a systematic review; rather it is an overview of the clinical trials, presented in the hopes of introducing overall information about clinical studies in Korea to the English-speaking world.

This review describes a number of clinical studies that were performed to compare the therapeutic effects of different kinds of acupuncture under certain conditions. Conventional acupuncture was compared with electric acupuncture, auricular acupuncture, BVA and manipulation. These comparative studies of different kinds of acupuncture are required in order to proceed with the most adequate method in the future. Since more than two therapies were simultaneously performed to treat the disorders in some studies, it is not likely to demonstrate the efficacy of pure acupuncture apart from other treatments. For instance, given that both acupuncture and auricular acupuncture were effective to treat tension-type headache patients, it is impossible to clarify the extent of the therapeutic benefit of acupuncture. Therefore, in order to investigate the therapeutic benefits of acupuncture, it is necessary to establish a group treated by acupuncture alone.

From the above clinical studies, it is possible to summarize the originality of Korean acupuncture by describing both of its characteristic approaches-individualized and practical. Firstly, a number of clinical studies in Korea have shown the benefits of individualized acupuncture treatment, such as Saam, Taegeuk or Eight constitutions acupuncture (35). Patel et al. (145) noted that individualized treatments significantly favored acupuncture, whereas formulaic approaches, in which all the patients received the same treatment, showed no significant difference. However, in order to demonstrate its superiority, more rigorous and well-designed randomized controlled clinical trials are urgently needed. Secondly, HA-like BVA have been used to treat a variety of painful conditions. HA is a new method of acupuncture where distilled herbal decoction is extracted and purified to be administered to an acupuncture point for stimulation. HA simultaneously exerts pharmacological actions from a bioactive compound isolated from herbal medicine and mechanical actions from acupuncture stimulation. The Korean medical world considers HA as a promising therapeutic method for various diseases $(84,140)$.

An individualized approach based on constitutional energy traits have been widely applied to a number of clinical trials in Korean medicine. HA have also been developed as a new therapeutic modality using integrated and practical approaches. Korean acupuncture in its own way is making a contribution to the emerging need for individualized and integrated approaches to acupuncture. In closing, we stress the need for randomized controlled studies and express our hope that this view into Korean traditional medical practice will lead to evidence-based studies that could form the basis for a metaanalysis in the near future.

\section{Acknowledgments}

We are grateful to Dr. Nam-Il Kim for presentation of the Figures. This study was supported by a grant of the Oriental Medicine R\&D Project, Ministry of Health \& Welfare, Republic of Korea (0405-OM00-0815-0001).

\section{References}

1. Eisenberg DM, Davis RB, Ettner SL, Appel S, Wilkey S, Van Rompay M, et al. Trends in alternative medicine use in the United States, 1990-1997: results of a follow-up national survey. J Am Med Assoc 1998;280: $1569-75$.

2. Panel NCD. NIH Consensus Development Panel. Acupuncture. J Am Med Assoc 1998;280:1518-24.

3. Yin CS, Park HJ, Chae YB, Ha EY, Park HK, Lee HS, Koh HG, Kang SG, Choi SM, Ryu YH, Lee HJ. Gnuine Korean Acupuncture: The individualized and practical approach. Neurol Res 2005: (submitted for publication).

4. Lee SY, Kim JH. The clinical observation of patient with headache treated by trigger point acupuncture therapy. J Oriental Pediatr Soc 1998;12: $133-43$.

5. Lee SM, Hwang KS, Han HC, Jeong HS. Clinical study of different effect between trigger point needling and remote acupuncture point needing on tension-type headache. J Kor Acu Mox Soc 2001;18:14-20.

6. Byun JY, Ahn SG. A clinical research of the auricular acupuncture therapy on headache. J Kor Acu Mox Soc 1995;12:355-63.

7. Kim YS, Kim SH. A clinical review on the effect of acupuncture (body and ears) treatment for strained headache. J Kor Oriental Med Soc 1996;17:433-46.

8. Kim JH, Lee JD, Choi DY, Ahn BC, Park DS, Lee YH. Clinical study of acupuncture effect on chronic headache. J Kor Acu Mox Soc 2000;17: $1-9$.

9. Kim YS, Kim CH. Eight cases of temporomanidular disorder. J Kor Acu Mox Soc 1996;13:429-35.

10. Byun JY, Ahn SG, Lee BC. Clinical study on the patients with temporomandibular disorders. J Kor Acu Mox Soc 1999;16:61-7.

11. Wang WH, Lim JK, Ahn KB, Jang HS, Shin JS. Clinical observation of temporomandibular disorder patients used Dong-Qi acupuncture treatment. J Kor Acu Mox Soc 2001;18:109-21.

12. Chun JK, Lee HI. Clinical study of painful neck disease. J East-West Med 1998;23:31-47.

13. Kim KO, Lee JS. The clinical effects of chuna treatment in painful neck disease. J Kor Manual Med 2000;1:67-82.

14. Choi SH, Oh MS, Song TW. Clinical studies on 52 cases of patient with cervical pain caused by traffic accident. J Oriental Rehabil Med 2000;10: 45-55.

15. Lee BR, Lee H, Park TG. Clinical studies on 50 cases of patient with cervical pain. J Kor Acu Mox Soc 1999;16:69-82.

16. Lee EY, Lee BR. A clinical observation for 25 cases of patients who are taken by chiefly complained of neck pain. J Kor Acu Mox Soc 1998;15: 393-406.

17. Lee GM, Kim KS, Um TS, Shin YM. A clinical study on the effects of the therapy of acupuncture on herniated cervical disc. J Kor Oriental Med Soc 1989;10:54-72.

18. Park SY, Lee BR. A clinical observation for the patients who are taken by frozen shoulder with the physical exercise problem. J Kor Acu Mox Soc 1999;16:17-25.

19. Cho HB, Lee GM. Clinical evaluation of acupuncture on frozen shoulder by DITI. J Kor Acu Mox Soc 1999;16:387-94.

20. Kim JK, Choi YT. Clinical study on the effect of acupuncture treatment for herniation on lumbar intervertebral disc. Kyunghee Med 1988;4: 425-31.

21. Jang SG, Hwang KJ, Lee H, Lee BR. Clinical reports on correlation between the different herniated type and oriental medical treatment. J Kor Acu Mox Soc 2001;18:68-81. 
22. Park SY, Lee BR. A clinical observation in herniation of lumbar intervertebral disc on plain lumbar CT. J Kor Acu Mox Soc 1998;15: 69-79.

23. Park SJ, Cho MR, Kim CS. Clinical study on 100 patient of low back pain. J Kor Acu Mox Soc 1999;16:119-35.

24. Byun JY, Lee JD. Clinical study on the conservative treatment in the different types of herniated lumbar intervertebral disc. Kor Int Med Soc 1998; 15:55-64.

25. Lee GM, Lee KC, Hwang YJ. Collaborative study of oriental-western medicine on HIVD. J Kor Acu Mox Soc 2000;17:1-10.

26. Kim JH, Lee JD. Assessment of bee venom acupuncture effect in herniated disc patient by rating scale. J Kor Oriental Med Soc 1999;20: 200-7.

27. Park TK, Lee YK, Lee BR. The clinical studies on 30 cases of patient with HNP by chuna treatment and analysis based on toes and foot shape. J Kor Acu Mox Soc 1999;16:27-39.

28. Kim HJ, Chung SH, Lee JS, Kim SS, Shin HD. The effect of microcurrent electrical neuromuscular stimulation on low back pain. J Oriental Rehabil Med 2001;11:1-14.

29. Park KW, Lee H, Lee BR. The clinical study on the stability of the lumbosacral angle of the patient suffering from low back pain. $J$ Kor Acu Mox Soc 1999; 16:41-55.

30. Mun HC, Hwang WJ, Lee GM, Cho NG, Gang SD, Cho JW, et al. The disc morphological changes on CT scan examinations after 5-7 years of acute HIVD patients who underwent oriental medical treatment. J Kor Acu Mox Soc 2001;18:1-12.

31. Park SY, Ahn SG. Comparative study between acupuncture and electroacupuncture on herniated intervetebral disc patients. J Kor Acu Mox Soc 1995; 12:273-82.

32. Park HS, Lee BR. The clinical study on the efficacy of the Dong-si acupuncture treatement. J Kor Acu Mox Soc 1997;14:15-34.

33. Lee H, Hwang WJ. The clinical study of the efficacy of the Sa-am acupuncture treatment. J Kor Acu Mox Soc 1999;16:1-16.

34. Yoon KB, Cho M, Jung H. The clinical study on the efficacy of the Ashi point. J Kor Acu Mox Soc 2001;18:226-36.

35. Chae SJ, Kim NO, Park YC, Son SS. Comparison of the improvement of subjective symptoms between body acupuncture group and eight constitution acupuncture group. J Kor Acu Mox Soc 2001;18:48-55.

36. Kim YS, Chae YS. Clinical studies on the effect of the electrical acupuncture stimulation therapy of low back pain in lumbar spondylosis. J Kor Oriental Med Soc 1989;10:113-28.

37. Jin JD, Lee JH, Lee SW, Seo JC, Han SW. A clinical study on patients of scoliosis. J Kor Acu Mox Soc 2001;18:11-23.

38. Heo SY. A clinical study on the outcome of chuna treatment of structural scoliosis by 25 cases. J East-West Med 1999;24:1-17.

39. Kim GM. Clinical studies on sciatica with low back pain. J Kor Oriental Med Soc 1992;9:88-100.

40. Lim JE, Song HS, Kwon SJ, Lee SN, Kang MS, Byun IJ, et al. A clinical study of the effects of acupuncture, moxibustion and Whuallak-tang (Huoluo-tang) on acute back pain and liver function. J Kor Acu Mox Soc 2001;18:43-9.

41. Lee SK, Yin CS. Clinical study of bee venom acupuncture therapy on ankylosing spondylitis. J Kor Inst Herbal Acu 1999;2:39-49.

42. Lee GM, Seong NG, Chae YS. Clinical study of stable thorarcolumbar vertebral fractures. J Kor Oriental Med Soc 1993;14:339-52.

43. Lee JG, Lee BR. The clinical study on 32 cases of patient with thoracolumbar compression fracture. J Kor Acu Mox Soc 1998;15: 427-36.

44. Lim JE, Kim KH, Hwang HS. The clinical study on 44 cases of patient with thoracolumbar compression fracture. J Kor Acu Mox Soc 2000;17: $41-51$.

45. Song WS, Hwang JY, Shin YI, Lee BR. The clinical study on Huatuojiajixue acupuncture treatment of patient with thoracolumbar compression fracture. J Kor Acu Mox Soc 2001;18:55-67.

46. Han SW. Oriental medical treatment of degenerative lumbar stenosis. J Kor Acu Mox Soc 1995;12:351-9.

47. Kim HJ, Lee SR, Byun JY, Ahn SG. Clinical study of the treatment of spondylolisthesis. J Kor Acu Mox Soc 2000;17:106-15.

48. Lee GM. Clinical evaluation acupuncture treatment on herniated intervertebral disc by digital infrared thermographic image. J Ког Аси Мох Soc 1994;11:275-82.

49. Lee GM, Lee SJ, Lee BC. Clinical evaluation of oriental medicine treatment of stable compression fracture by DITI. J Kor Acu Mox Soc 1997;14:9-20.
50. Cho NG, Kim KS. Comparative study between electroacupuncture and acupuncture on herniated intervertebral disc by using digital infrared thermographic image. J Kor Acu Mox Soc 1997;14:21-30.

51. Hur TY, Cho NG, Cho EH, Cheon MN. Clinical evaluation of acupuncture on spondylolisthesis by DITI. J Kor Acu Mox Soc 2000;17:31-9.

52. Jeong SH, Kim SJ, Lee EY. The clinical study of the association between cigarette smoking and effect of oriental medical treatment in low back pain. J Kor Acu Mox Soc 2001;18:32-45.

53. Heo SY, Kim KH. Investigation on the correlation improvement rate of symptoms with Moire topography analytic improvement rate. $J$ Kor Manual Med 2000;1:55-65.

54. Heo SY, Kang HS. Investigation on chuna treatment for low back pain and sciatica. J East-West Med 1999;24:14-26.

55. Lee GM, Seong NG. A clinical study of the effects of the therapy on knee joints with osteoarthritis. J Kor Oriental Med Soc 1991;12: $147-59$.

56. Koh KS, Kang SK. Clinical observation on degenerative arthritis of knee joint. J Kor Oriental Med Soc 1987;8:66-72.

57. Na CS, Ahn BC. A clinical study on degenerative arthritis of knee joint. J Kor Oriental Med Soc 1992;13:202-11.

58. Woo YM, Lee JH, Kim JM, Nam Y. Clinical study of acupucnture effect on microtraumatic injuries of the knee joint. J Kor Acu Mox Soc 2000;17: 88-99.

59. Wang WH, Ahn KB, Lim JK, Jang HS. Clinical investigation compared with the effects of the bee venom acupuncture on knee joint with osteoarthritis. J Kor Acu Mox Soc 2001;18:35-47.

60. Kim JH, Lee JD. Clinical research of bee venom acupuncture analgesic effect on osteoarthritis. J Kor Acu Mox Soc 1999;16:25-37.

61. Hwang YJ, Lee GM, Hwang WJ, Seo EM, Jang JD, Yang GB, et al. Clinical research of bee venom acupuncture effects on rheumatoid arthritis. J Kor Acu Mox Soc 2001;18:33-42.

62. Hwang WJ. Clinical study of rheumatoid arthritis. J Kor Acu Mox Soc 1995; 12:281-90.

63. Shim JC, Kim YJ, Suh JK, Chung CW, Kang GB, Hwang YH, et al. Clinical study of electrical stimulation of the peripheral nerve. $J$ Kor Soc Anesth 1984;17:126-35.

64. Cho KS, Kim SC, Lee JY, Sohn SS, Park DS. The effect of acupuncture on the post-thoracotomy pain control. Kor J Thorac Cardiovasc Surg 1997;30:187-94.

65. Choi H, Moon SJ. A clinical study on reviewing pain of acupuncture. J Kor Acu Mox Soc 1983;1:40-5.

66. Kim YI, Kim YH, Lee H, Lee BR. Clinical comparison studies on 26 cases of patient with ankle sprain with acupuncture treatment group and trigger point treatment group. J Kor Aси Mox Soc 2001;18: 50-9.

67. Bang DH, Chang HS, Han SW, Ryu SH, Lee IG. A clinical observation of patients with humeral lateral epicondylitits. J Kor Oriental Med Soc 1992;13:224-9.

68. Seung JW, Ahn CB. A study on human immune activity of the arthritis and multi-neuritis through different moxibustion methods. J Kor Acu Mox Soc 1991;8:395-403.

69. Choi YT, Lee HJ. A study of acupuncture treatment effect on the acute gout disease. J Kor Oriental Med Soc 1989;10:132-7.

70. Ahn KB, Wang WH, Lim JK, Jang HS. Clinical study of acupuncture effect by measuring amperage from chong points. J Kor Acu Mox Soc 2001;18:13-21.

71. Ha CH, Han SG, Cho MR, Ryu CR, Lee BR. A clinical study on 29 cases with stroke treated by common acupuncture therapy and scalp acupuncture. J Kor Acu Mox Soc 2001;18:82-90.

72. Lee KJ, Koo BS, Kim YS, Kang JK, Moon SK, Koh CN, et al. Effects of venesection at the Sybsun-points on blood pressure and body temperature in patients with stroke. J Kor Oriental Med Soc 2000;21:62-7.

73. Park SU, Moon SK, Koh CN, Cho KH, Kim YS, Bae HS, et al. The clinical study of the effect of electrical stimulation at Sugu-Sungjang points (GV26-CV24) on blood pressure, pulse, and cerebral blood flow in ischemic stroke patients. Kyunghee Med 1997;13:390-403.

74. Ahn CH, Bae HS, Roh JH, Moon SK, Koh CN, Cho KH, et al. Effects of auricular acupuncture on the mild hypertension. J Kor Oriental Med Soc 2000;20:93-7.

75. Kang BJ, Moon SK, Koh CN, Cho KH, Kim YS, Bae HS, et al. Clinical research on the depressing effect of acupuncture therapy at Kokchi (LI1) and Chocksamni (ST36) in acute stroke patients with hypertension. J Oriental Med 1998;3:43-50. 
76. Moon SK, Cho KH, Koh CN, Kim YS, Bae HS, Lee KS. Effects of opposing needling on upper limb on cerebral blood flow in ischemic stroke patients. Kyunghee Med 2000;16:94-101.

77. Song JC, Jung SH, Lee JS, Kim SS, Shin HD. Clinical study of the effect of electroacupuncture on shoulder pain of the cerebrovascular attack patients. J Oriental Rehabil Med 1999;9:41-57.

78. Yin CS, Nam SS, Kim YS, Lee JD, Kim CH, Koh HK. Effects of honey bee venom acupuncture therapy on poststroke hemiplegic shoulder pain. J Kor Inst Herbal Acu 2000;3:213-32.

79. Kang JC, Baik TH. A comparative study of effects using physical treatment apparatus and diagnosis of shoulder pain on cerebrovascular attack patients. Kor Int Med Soc 1999;20:244-60.

80. Lee SH, Lee YH. Clinical study with thermography on shoulder hand syndrome after stroke. J Kor Oriental Med Soc 1997;18:25-39.

81. Kang KS, Jeong EJ, Moon SK, Koh CN, Cho KH, Kim YS, et al. Clinical study on the effects of moxibustion for post-stroke voiding dysfunction. J Kor Oriental Med Soc 2000;21:236-41.

82. Lee YK, Lee BR. Clinical studies on 72 cases of patient with facial paralysis. J Kor Acu Mox Soc 1998;15:1-12.

83. Lee SW, Han SW. Clinical study of facial nerve paralysis through electroacupuncture treatment. J Kor Acu Mox Soc 1999;16: $149-63$.

84. Yun JH, Yook TH, Song BY. The effect of Hominis placenta herbal acupuncture. J Kor Inst Herbal Acu 2000;3:89-99.

85. Lee KM. Combined treatment method for peripheral facial paralysis: report on 85 cases. J Kor Acu Mox Soc 1998;15:21-9.

86. Cho EH, Cho NG, Hur TY, Cheon MN. Clinical evaluation of acupuncture and herb medication on Bell's palsy by DITI. J Kor Acu Mox Soc 2000;17:19-30.

87. Song BY, Sohn IC, Kim KS. Clinical diagnostic study on prognosis of Bell's palsy with the digital infrared thermal image. J Kor Acu Mox Soc 1999;16:13-35.

88. Kang MJ, Kim KH, Hwang HS. Comparative clinical study between oriental medicine and oritental western medicine treatment on facial nerve paralysis. J Kor Acu Mox Soc 2000;17:55-66.

89. Kim CG, Park SD, Kim KH. Comparative study between acupuncture and acupuncture-oriental herb medicine treatment on facial nerve paralysis. J Kor Acu Mox Soc 2001;18:10-22.

90. Kwon SJ, Song HS, Kim KH. The influence of moxibustion and basic compound therapy on peripheral facial paralysis. J Kor Acu Mox Soc 2000;17:160-71.

91. Sim MK, Hwang WJ, Lim KS. Clinical study of acupuncture and venesection on acute infectious conjunctivitis. J Kor Oriental Med Soc 1993;14:133-8.

92. Kim KJ, Chae BY. A clinical analysis on glaucoma, cataract and causing blindness by oriental medical therapy. J Oriental Med Surg Ophthalmol Otolaryngol 1997;10:340-8.

93. Choi DY, Kim JK, Kim SS. A clinical study of the effect of acupuncture and moxibustion treatment for the near-sightedness. Kor. J Oriental Med Pathol 1999;13:119-23.

94. Chae BY. The clinical study on decrease of visual acuity. J Oriental Med 1997;2:93-108.

95. Kim SS, Kim JK, Choi DY. A clinical study of the effect of oriental medicine and acupuncture treatment for the amblyopia. J Kor Oriental Med Soc 2000;20:23-8.

96. Kim SI, Park DI. A clinical study on allergic rhinitis. Kor Int Med Soc 1998;19:353-63.

97. Seo JC, Lee JD. Clinical study on chronic paranasal sinitis by nasal acupuncture. J Kor Acu Mox Soc 2000;17:99-105.

98. Kim YB, Yoon SH. A clinical observation of the nasal acupuncture therapy on nasal obstruction. J Oriental Med Surg Ophthalmol Otolaryngol 1999;12:205-11.

99. Park GH, Han YM, Ahn SH, Hwang CH. Effect of tinnitus after bleeding, acupuncture, moxa, and laser treatment. J Oriental Med Surg Ophthalmol Otolaryngol 1999;12:396-407.

100. Kim GJ. A clinical analysis on the treatment efficiency of tinnitus by types of bianzheng. J Oriental Med Surg Ophthalmol Otolaryngol 1999;12:182-8.

101. Lee HB, Oh SJ, Kim SK. Clinical study on otitis media with effusion by acupucnture. J Kor Acu Mox Soc 2001;18:92-8.

102. Chae BY. The clinical study of acne patients. J Oriental Med Surg Ophthalmol Otolaryngol 1998;11:251-68

103. Kim JS, Kim GJ. The clinical observation of 8 cases of acnes diseases. J Oriental Med Surg Ophthalmol Otolaryngol 2001;14:66-75.
104. Byun JY, Ahn SG. Effects of the auricular acupuncture on the blood pressure. J Kor Oriental Med Soc 1996;17:418-26.

105. Lee BH, Kim CH, Seo JC, Youn HM, Jang KJ, Song CH, et al. The effects of moxibustion on blood pressure of hypertentsion patients. J Kor Acu Mox Soc 2001;18:70-6.

106. Hwang BT, Hwang WJ, Shin SY. Clinical research of the acupuncture therapy on stop-smoking. J Kor Acu Mox Soc 1994;11:265-74.

107. Ahn SG, Kim SC, Lee MH, Kim KS. A clinical research of the auricular acupuncture therapy. J Kor Acu Mox Soc 1993;10:175-90.

108. Choi SC, Hwang CY. Effects on stop of smoking in adolescents by auricular acupuncture therapy. J Oriental Med Surg Ophthalmol Otolaryngol 1999;12:369-85.

109. Choi DY. Clinical study of effect of auricular acupuncture on stoping smoking. J Kor Acu Mox Soc 1996;13:202-11.

110. Lee JD, Choi DY, Park DS. Clinical research of the auricular acupuncture therapy on stop-smoking. J Kor Acu Mox Soc 1992;9:17-29.

111. Kim JD, Kwan CC, Lim NC. Clinical study of the effect of ear acupuncture on 233 alcoholics. J Kor Oriental Med Soc 1992;13:124-50.

112. Lee JH, Kim YC, Woo HJ. Clinical study on 133 cases of temperance (quit-drinking) therapy. J Oriental Med 1998;3:59-69.

113. Park JH, Peun SH. Clinical study of auricular acupuncture and herbal medicine in the treatment of alcoholism. J East-West Med 1996;21:1-15.

114. Lee SR, Lee KG. A clinical research of abdominal obesity by the electric acupuncture therapy. J Kor Acu Mox Soc 1996;17:336-44.

115. Jeong SH, Nam SS, Kim YS, Lee JD, Choi DY, Koh HK, et al. A clinical study on case of nine obesity patients by elecroacupuncture therapy. J Kor Acu Mox Soc 1999;16:39-56.

116. Lee ES, Kim YS. The effect of acupuncture treatment on weight regulation. J Oriental Rehabil Med 1996;6:365-77.

117. Kim YS, Kim CH, Kim KS. Effect of auricular acupuncture on postoperative nausea and vomiting. J Kor Acu Mox Soc 1996;17:331-6.

118. Kim KS, Kim DS, Shin KI, Kim YS. Effect of electric acupuncture stimulation of PC6 and PC7 antiemetic point on postoperative nausea and vomiting. J Kor Soc Anesth 1995;28:433-40.

119. Kim SW, Nam SS, Lee SK, Kim KS, Kim JK. The effects of electrostimulation on acupuncture loci upon duration of labor in primipara. Kyunghee Med 1999;15:198-202.

120. Kim JK, Kim SW. A clinical study on the effects of acupuncture anesthesia upon 31 cases of curettage. Kyunghee Med 1992;8:276-85.

121. Hwang WJ, Yang GB. The study on the effects of moxibustion on peripheral blood circulation. J Kor Oriental Med Soc 1997;18:499-505.

122. Ahn YM, Ahn SY, Doo HK. The change of temperature of external genitalia at the patients with impotence by using penile DITI. Kyunghee Med 1998;14:79-88.

123. You WK, Lee MJ, Oh JG. The effects of auricular acupuncture for obesity on the change of hormone and energy metabolism during weight control of veteran taekwondo players. J Oriental Rehabil Med 2000;10: 133-45.

124. Park KM. Influence of acupuncture stimulation on electrical resistance under adiaphoresis induced by regional anaesthesia. J Kor Acu Mox Soc 2000;17:130-8.

125. Youn JH, Hwang MS, Bae GT, Lee SH, Lee SD, Jang JH, et al. The new finding on BOLD response of motor acupoint KI6 by fMRI. $J$ Kor Acu Mox Soc 2001;18:5.

126. Kim ID, Oh HH, Song HC, Bom HS, Byun JY, Ahn SG. The nuclear medical study on the effect of ST36 electroacupuncture on cerebral blood flow. J Kor Acu Mox Soc 2001;18:18-26.

127. Oh HH, Byun JY, Kim ID, Ahn SG, Mun HC, Hwang WJ, et al. The nuclear medical study on the effect of LI4 acupuncture on cerebral blood flow. J Kor Acu Mox Soc 2001;18:46-54.

128. Woo YM, Nam Y. The practical study of the contralateral therapeutic theory in acupuncture approach about the changes in the blind spot mapping pre and post acupuncture. J Oriental Med Surg Ophthalmol Otolaryngol 2000;13:200-10.

129. Lee SH, Lee JD, Lee YH. Thermographic study on the effects of acupuncture at Hapkok (LI4) in normal cases. J Kor Acu Mox Soc 1995; 12:49-64.

130. Sohn IC, Kim DM, Kim HJ, Lee HS, Kim KS. Effects on the thermal changes of Hap-Kok (LI4) and Chun-Choo (ST25) following acupuncture on Hap-Kok (LI4) in man. J Kor Acu Mox Soc 1998;19: 66-88.

131. Han MC, Chung HC, Koo ST, Ahn SH, Kim KS, Sohn IC. Effects of acupuncture at left Hap-kok (LI4) on the skin temperature changes of Young-Hyang (LI20) area. J Kor Acu Mox Soc 1999;16:57-68. 
132. Song JS, An SH, Kim JH, Kim KS, Sohn IC. Effects on the thermal changes of Kok-Chi (LI4) and Yong-Hyang (LI20) following acupuncture on Hap-Kok (LI4) in man. J Kor Acu Mox Soc 1998;19:271-95.

133. Han MJ, Chung HC, Koo ST, Ahn SH, Kim KS, Sohn IC. Effects of acupuncture at left Hap-Kok (LI4) on the skin temperature changes of Young-Hyang (LI20) area. J Kor Acu Mox Soc 1999;16:57-68.

134. Hwang JH, Ahn SH, Kim KS, Sohn IC. Effects of acupuncture at Hap-Kok (LI4) on the thermal changes of abdominal surface in man. J Kor Acu Mox Soc 1999;16:445-72.

135. Yun JH, Hwang CY, Lim KS. Effects on the thermal changes of the face follow electroacupuncture on Hapkok (LI4) and Samgan (LI3). J Oriental Med Surg Ophthalmol Otolaryngol 1999;12:222-47.

136. Lee SW, Lee JH, Song BY, Yook TH. The effect on the thermal changes of an acupuncture point area with the Young-Su-Bo-Sa acupuncture stimulation. J Kor Acu Mox Soc 2001;18:161-74.

137. Song BY, Sohn IC, Kim KS. Effects on the thermal changes of the corresponding meridian points following the left or right rotary acupuncture stimulation. J Kor Acu Mox Soc 1999;16:385-402.

138. Song BY, Yook TH. Effect of the thermal changes of Five-shu-points of the lung meridian with acupuncture stimulation on Taeyon (L9). $J$ Kor Acu Mox Soc 2000;17:219-32.
139. Kim YH, Song BY, Yook TH. Effects of the thermal changes of the Taeyon (L9) and the Chungbu (L1) area following acupuncture stimulation on Taeyon (L9) in man. J Kor Acu Mox Soc 2001;18: 77-91.

140. Yook TH, Song BY, Shim MS, Kim BH, Park JJ, Yun JH. Effects on the local thermal change following herbal acupuncture on DITI. J Kor Acu Mox Soc 2000;17:57-68.

141. Kim HJ, Byun JY, Ahn SG, Lee GM, Park YH, Kim KS. Effects on the thermal changes of the ankle region following acupuncture on Wu-hu. J Kor Acu Mox Soc 2001;18:40-9.

142. ter Riet G, Kleijnen J, Knipschild P. Acupuncture and chronic pain: a criteria-based meta-analysis. J Clin Epidemiol 1990;43:1191-9.

143. Ezzo J, Berman B, Hadhazy V, Jadad A, Lao L, Singh B. Is acupuncture effective for the treatment of chronic pain? A systematic review. Pain 2000;86:217-25.

144. Park J, Hopwood V, White A, Ernst E. Effectiveness of acupuncture for stroke: a systematic review. J Neurol 2001;248:558-63.

145. Patel M, Gutzwiller F, Paccaud F, Marazzi A. A meta-analysis of acupuncture for chronic pain. Int J Epidemiol 1989;18:900-6.

Received January 26, 2005; accepted July 4, 2005 


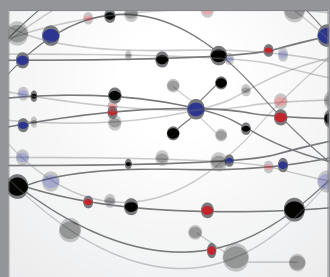

The Scientific World Journal
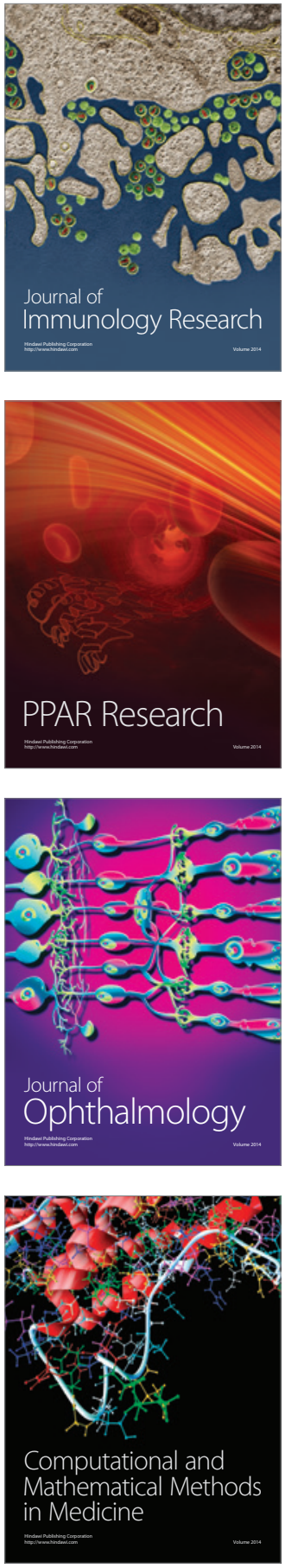

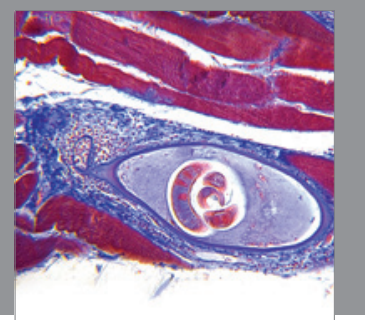

Gastroenterology

Research and Practice
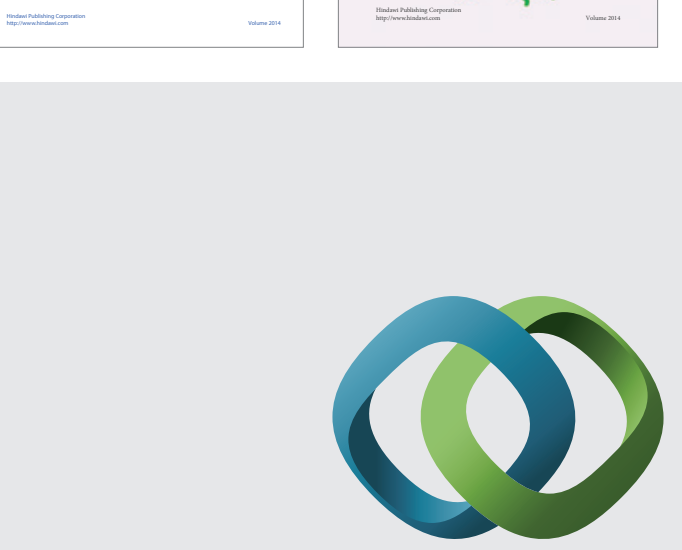

\section{Hindawi}

Submit your manuscripts at

http://www.hindawi.com
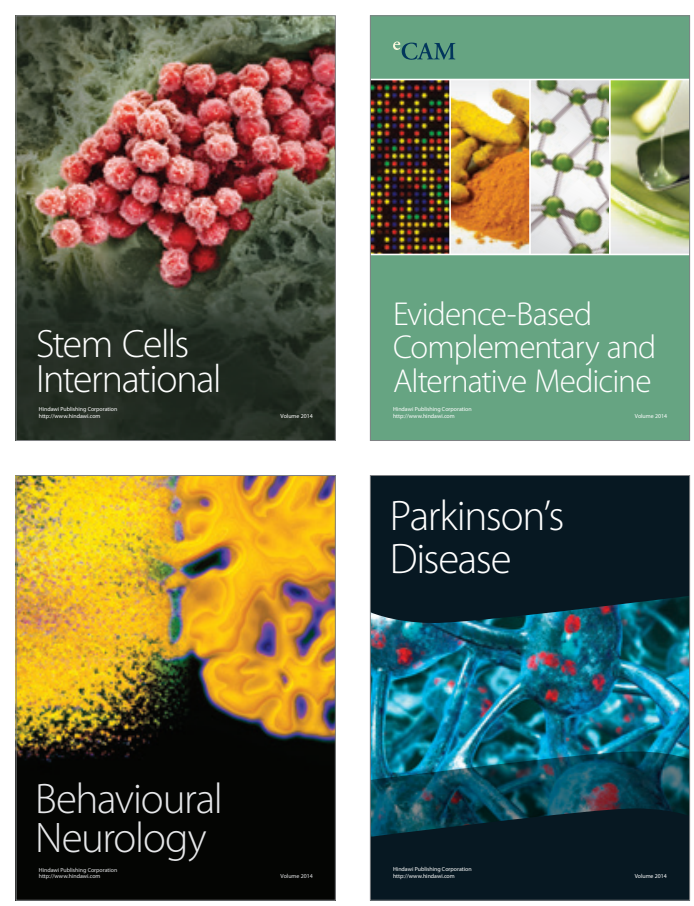

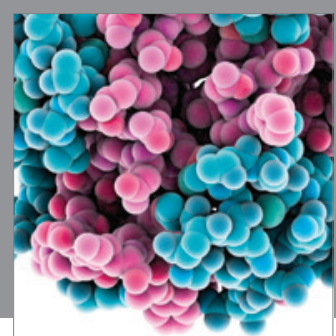

Journal of
Diabetes Research

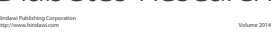

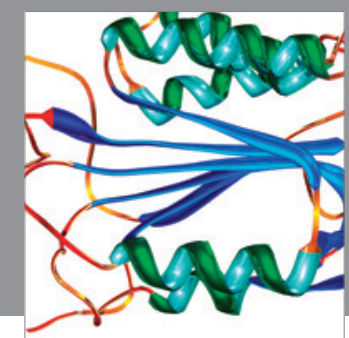

Disease Markers
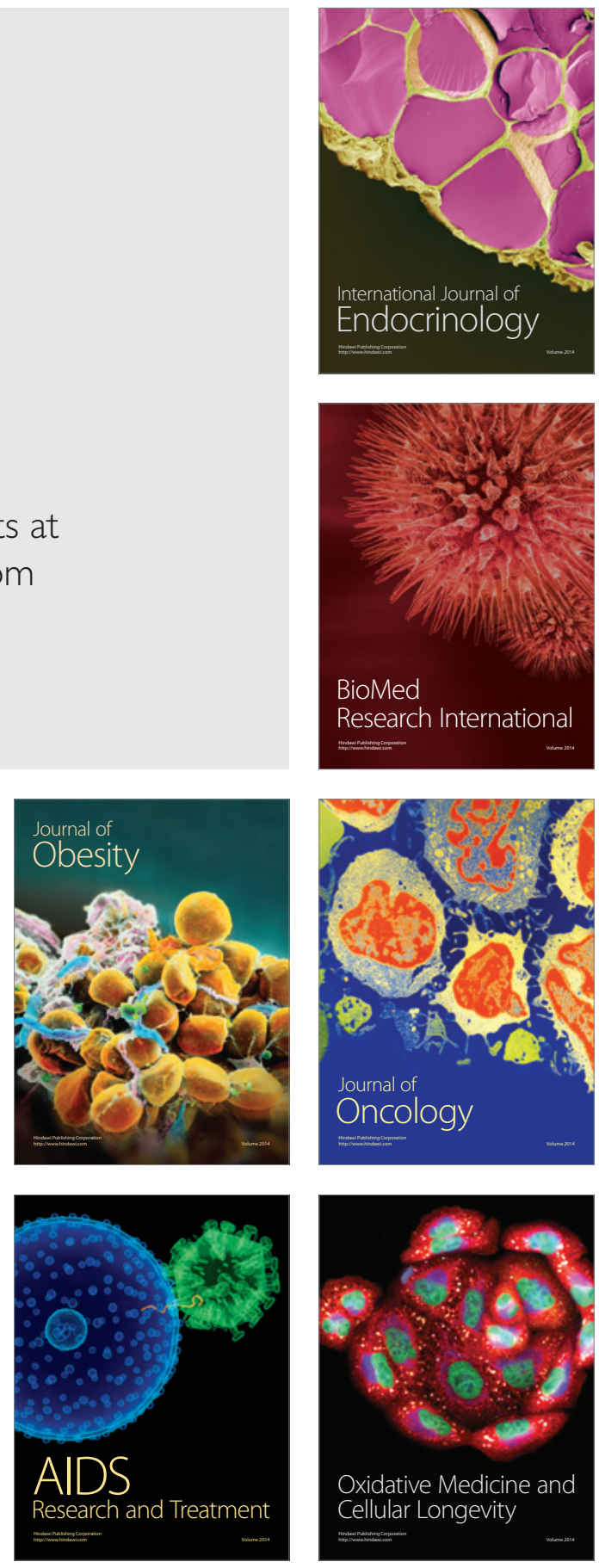